\title{
A Microstructurally Resolved Model for Li-S Batteries Assessing the Impact of the Cathode Design on the Discharge Performance
}

\author{
Vigneshwaran Thangavel, ${ }^{\mathrm{a}, \mathrm{b}}$ Kan-Hao Xue, ${ }^{\mathrm{a}, \mathrm{b}, \mathrm{c}}$ Youcef Mammeri, ${ }^{\mathrm{d}}$ Matias Quiroga, ${ }^{\mathrm{a}, \mathrm{b}, \mathrm{h}}$ \\ Afef Mastouri, ${ }^{\text {,b }}$ Claude Guéry, ${ }^{\text {, b,e }}$ Patrik Johansson,,${ }^{\text {,e,f }}$ Mathieu Morcrette,, ,b,e \\ and Alejandro A. Franco ${ }^{a, b, e, g, *, z}$ \\ ${ }^{a}$ Laboratoire de Réactivité et Chimie des Solides (LRCS), CNRS UMR 7314, Université de Picardie Jules Verne, \\ 80039 Amiens Cedex, France \\ ${ }^{b}$ Réseau sur le Stockage Electrochimique de l'Energie (RS2E), Fédération de Recherche, CNRS 3459, France \\ ${ }^{c}$ School of Optical and Electronic Information, Huazhong University of Science and Technology, Wuhan 430074, \\ People's Republic of China \\ ${ }^{d}$ Laboratoire Amiénois de Mathématique Fondamentale et Appliquée (LAMFA), CNRS UMR 7352, \\ Université de Picardie Jules Verne, 80039 Amiens Cedex, France \\ ${ }^{e}$ ALISTORE-European Research Institute, Fédération de Recherche CNRS 3104, 80039 Amiens Cedex, France \\ ${ }^{f}$ Department of Physics, Chalmers University of Technology, SE-412 96 Göteborg, Sweden \\ ${ }^{g}$ Institut Universitaire de France, 75005 Paris, France
}

This paper reports a discharge model for lithium sulfur (Li-S) battery cells, supported by a multi-scale description of the composite $\mathrm{C} / \mathrm{S}$ cathode microstructure. The cathode is assumed to be composed of mesoporous carbon particles with inter-particular pores in-between and the sulfur impregnated into both types of pores. The electrolyte solutes such as sulfur, polysulfides and lithium ions, produced during the discharge, are allowed to exchange between the pores. Furthermore, the model describes the $\mathrm{Li}_{2} S_{(\text {solid })}$ precipitation and its effects on transport and reduction reaction kinetics. Hereby it provides fundamental insights on the impact on the Li-S discharge curve of practically modifiable manufacturing parameters and operation designs, such as current density, carbon porosity, $\mathrm{C} / \mathrm{S}$ ratio and sizes of carbon particles and pores.

(C) The Author(s) 2016. Published by ECS. This is an open access article distributed under the terms of the Creative Commons Attribution 4.0 License (CC BY, http://creativecommons.org/licenses/by/4.0/), which permits unrestricted reuse of the work in any medium, provided the original work is properly cited. [DOI: 10.1149/2.0051614jes] All rights reserved.

(cc) BY

Manuscript submitted June 21, 2016; revised manuscript received October 3, 2016. Published October 19, 2016. This was Paper 2181 presented at the San Diego, California, Meeting of the Society, May 29-June 2, 2016.

Lithium-ion battery technologies based on dual intercalation electrodes have come to totally dominate the consumer electronics market for mobile devices. ${ }^{1,2}$ However their capacities still limit the driving ranges and user modes for both electric and hybrid electric vehicles,${ }^{3}$ despite approaching the intrinsic maximum for intercalation reactions. ${ }^{4,5}$ With the demand for batteries with even higher capacities, lithium sulfur (Li-S) batteries, ${ }^{6,7}$ with a theoretical capacity of $1672 \mathrm{mAh} . \mathrm{g}^{-1}$ based on cathode solid sulfur mass ${ }^{8}$ and a potential gravimetric energy density of about $600 \mathrm{Wh} \cdot \mathrm{kg}^{-1},{ }^{9}$ has (re-)gained attention in recent years. ${ }^{10-23} \mathrm{Li}-\mathrm{S}$ batteries usually have a lithium metal anode, a porous separator, and a porous $\mathrm{C} / \mathrm{S}$ composite cathode where the carbon acts as a host and provides electronic wiring for the insulating sulfur, existing as $S_{8(\text { solid) }}$ and $\mathrm{Li}_{2} S_{\text {(solid) }}$. The pores in both the cathode and the separator are filled with an aprotic electrolyte, e.g. $1 \mathrm{M}$ LiTFSI dissolved in dimethoxyethane (DME): 1,3-dioxolane (DOL) $\left(1: 1\right.$ volume ratio). ${ }^{24}$ There is a general consensus that the reasons behind the theoretical capacity of Li-S batteries not being achieved are short-comings: low sulfur utilization due to poor wiring and soluble polysulfide intermediates giving rise to a parasitic shuttle effect. $^{25,26}$

One breakthrough in the last decade was the finding that a host of mesoporous carbon greatly enhanced the active material utilization as compared to a ground $\mathrm{C} / \mathrm{S}$ mixture. ${ }^{5}$ The mesoporous architecture of the cathode primarily assisted in retaining polysulfide intermediates in the cathode. ${ }^{27}$

Theory and mathematical modeling are powerful tools to assist the optimization of electrochemical devices, by providing insight in operating principles and identifying limitations. ${ }^{28-30}$ Continuum models applied to Li-S batteries have been successful in simulating various battery operation phenomena. ${ }^{31-37}$ However, most of the continuum models reported so far model the cathode as a homogenous porous medium, described by an effective porosity, not accounting for the microstructure, thus not enabling any study of the impact of different architectures. In contrast, Danner et al. developed a full cycle model using a mesoporous cathode containing microporous carbon particles. ${ }^{38}$ However, this model assumes the sulfur based species to be electrochemically active only as long as they remain confined in the micropores within the carbon particles, hence ignoring the transport of these species along the cell and their electrochemistry over the external surface of the carbon particles. Recently, Dysart et al. reported a multi-scale analysis of Li-S batteries using a stochastic model to reconstruct the cathode microstructure ${ }^{39}$ and calculated the associated effective transport properties, but without dynamically evolving the microstructure upon discharge.

In this paper we report a multi-scale model devoted to the simulation of discharging Li-S cells using a cathode made up of mesoporous carbon particles with inter-particular pores in-between. Our model brings novel features such as the consideration of the mass exchange of all the electrolyte solutes between mesopores within carbon particles and inter-particular pores, of the chemical and electrochemical reactions in both types of pores, and of the dynamical evolution of species diffusion coefficients. The novel features in our model permit the exploration of the impact on the discharge performance of properties such as the inter-particular porosity between the carbon particles, the mesoporosity within the carbon particles, the particle and the mesopore sizes, and the sulfur loading at two different pore scales. These are features either impossible to study or simply not studied in previously reported models. In the following, we present the physical and geometrical assumptions and demonstrate how it can be utilized to study the effects of the initial cathode microstructure and sulfur repartition within on the overall discharge cell performance. Although our model has limitations due to assumptions and assumed parameters, it can still qualitatively predict experimentally observed discharge trends and provide insights on the limiting reasons behind them.
*Electrochemical Society Member.

${ }^{\text {h}}$ Present address: Institut Charles Gerhardt, CNRS and Université Montpellier 2, 34095 Montpelier, France.

${ }^{\text {z} E-m a i l: ~ a l e j a n d r o . f r a n c o @ u-p i c a r d i e . f r ~}$

\section{Methodology: Overall Assumptions}

The assumptions on which our model (Figure 1) is based are the following: 


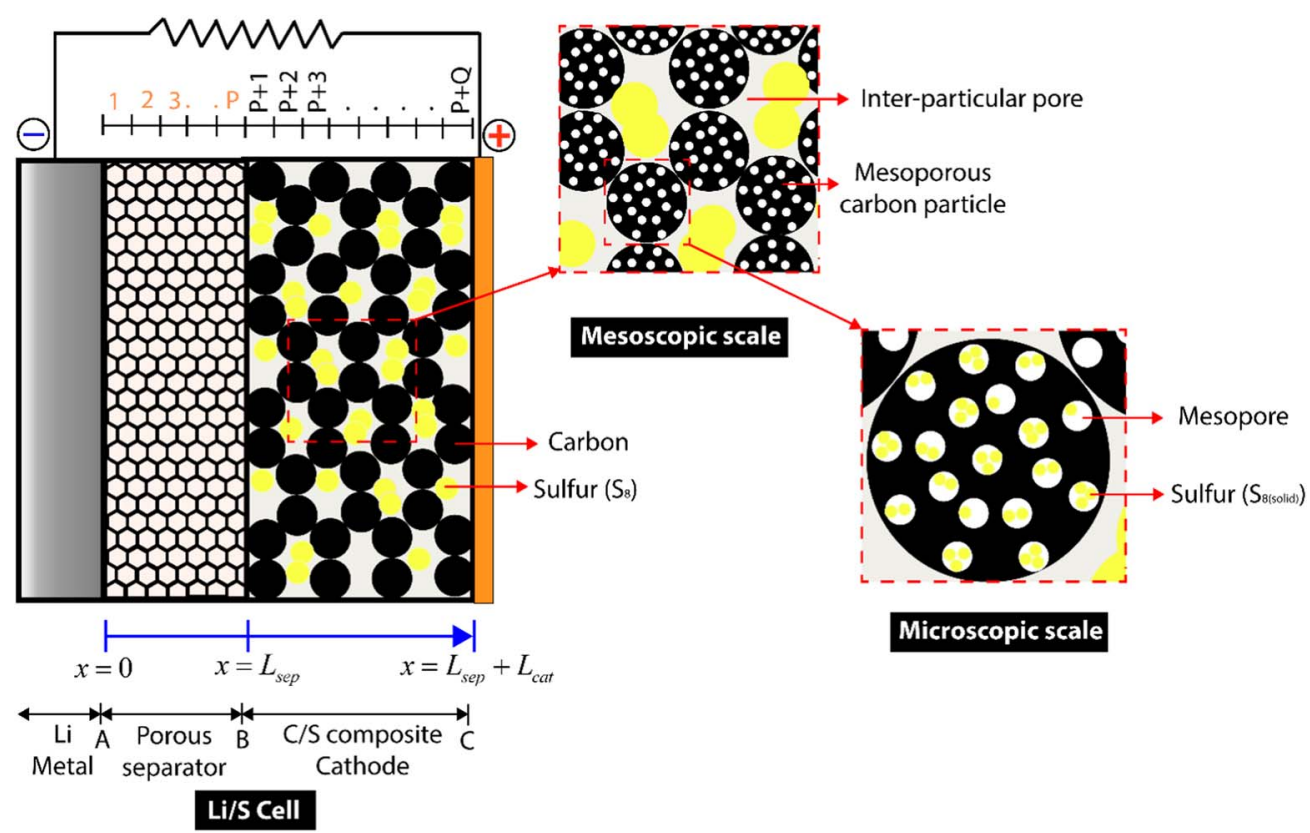

Figure 1. Schematic representation of our Li-S cell model at various resolutions.

- The separator and cathode components are represented in onedimension;

- The cathode consists of mesoporous spherical carbon particles with an uniform size distribution;

- Each carbon particle contains spherical mesopores with an uniform pore size distribution;

- The impregnated sulfur initially exists both in mesopores within the carbon particles and in the inter-particular pores between them;

- The active surface area of the mesopores within each carbon particle is assumed to remain unchanged after loading $S_{8(\text { solid })}$ inside them;

- Transport of all the electrolyte solutes, such as sulfur, polysulfides, and lithium ions, is considered along the cell, as well as their mass exchange between the mesopores within the carbon particles and inter-particular pores;

- The transport of the electrolyte solutes is assumed to be diffusive and thus described by using Fick's laws;

- The diffusion coefficients of the solutes are assumed to depend on the electrolyte viscosity, calculated on-the-fly as dependent on the concentration of long chain polysulfides;

- Due to precipitation/dissolution reactions the porous volume of the cathode evolves along the discharge which is assumed to be completely filled with electrolyte;

- The concentration of the dissolved species in the electrolyte evolve due to transport, electrochemical and precipitation/dissolution reactions and their resulting evolution of porous/electrolyte volume.

- The equilibrium potentials of all the electrochemical reactions follow Nernst's equations;

- The porous carbon matrix is perfectly percolated allowing proper electron wiring for all the particles;

- The carbon is assumed to be a perfect electronic conductor;

- The cathode surface area and porosity losses due to the presence of binder are neglected.

- The electrochemical reaction kinetics are assumed to follow the Butler-Volmer equations;

- The capacitive current due to the electrochemical double layer effect is neglected;

- The parasitic chemical and electrochemical reactions involving the polysulfide species reduction at the anode are neglected.
For the discharge reaction scheme at the anode we simply assume that lithium metal oxidation takes place, while at the cathode the reaction mechanism is assumed to be much more complex. Here, a part of the solid sulfur $\left(S_{8(\text { solid })}\right)$ contained in the cathode dissolves into the electrolyte to produce uncharged solvated sulfur $\left(S_{8(s o l n)}\right)$. The solvated sulfur subsequently undergoes a series of reduction reactions to produce di-anion sulfides $\left(S_{(s o l n)}^{2-}\right)$. The reduction reactions take place in the electrolyte by accepting electrons from the surface of the carbon particles. The cathode reduction reactions and the anode side oxidation reactions are listed in Table I. The cathode reactions can take place both in the mesopores of the carbon particles and in the inter-particular pores. For the sake of clarity all the electrochemical reactions were indexed with angular brackets " \langle\rangle ".

The solvated lithium salt concentration in the electrolyte is assumed to be $1000 \mathrm{mM}(1 \mathrm{M})$, however in order to ascertain electroneutrality, the initial lithium ion concentration (Table I) is determined by the total negative charge due to the anion of lithium salt and polysulfides ions.

Assumed parameters are calibrated by qualitatively matching the calculated discharge profile trends with those experimentally observed for different current densities or C-rate. ${ }^{40-42}$

The solvated polysulfides $\left(S_{y(s o l n)}^{2-}\right)$ may react with lithium ions $\left(L i_{(s o l n)}^{+}\right)$and produce insoluble lithium polysulfide that precipitates $\left(\mathrm{Li}_{2} \mathrm{~S}_{y(\text { solid })}\right)$. These chemical reactions are reversible, hence termed as precipitation/dissolution reactions (Table II), and indexed by curly brackets " \{\} ".

All parameters and expressions corresponding to inter-particular pores are henceforth assigned the subscript 1 and those of the mesopores within the carbon particles subscript 2.

The mathematical flow chart of our model is shown in Figure 2, where the global input is the applied current density and the global output is the electrode potential.

The electrochemical reaction rates depend on the current density, the concentration of electrolyte solutes and the active surface area of the cathode. The precipitation/dissolution reaction rates depend on the concentration of electrolyte solutes and the volume fraction of precipitates in the cathode. The concentration of electrolyte solutes evolve with the discharge and is coupled to the precipitation of $\mathrm{Li}_{2} \mathrm{~S}_{y(\text { solid) }}$, whereby the porosities and the active surface area of the cathode also evolve with the discharge, which in turn affect the chemical/electrochemical reaction rates and the transport of electrolyte 
Table I. Electrochemical reactions and physical parameters.

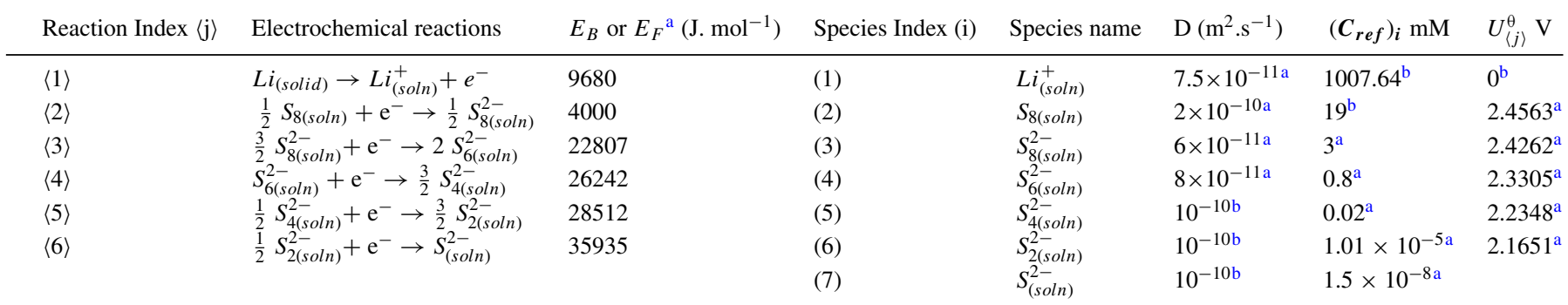

assumed parameters.

bParameters taken from Ref. 31.

Table II. Precipitation/dissolution reactions and physical parameters.

\begin{tabular}{|c|c|c|c|c|c|}
\hline Reaction Index $\{\mathrm{k}\}$ & Precipitation/dissolution reactions & $k_{\{k\}}{ }^{\mathrm{a}}\left(\mathrm{mol}^{2} \cdot \mathrm{m}^{-6} \cdot \mathrm{s}^{-1}\right)$ & Species name & $K_{\{k\}}\left(\mathrm{mol}^{3} \cdot \mathrm{m}^{-9}\right)$ & Molar volume $\left(\mathrm{m}^{-3} \cdot \mathrm{mol}\right)$ \\
\hline$\{1\}$ & $S_{8(\text { solid })} \leftrightarrows S_{8(\text { soln })}$ & $35\left(\mathrm{~s}^{-1}\right)$ & $S_{8(\text { solid })}$ & $19\left(\mathrm{~mol} \cdot \mathrm{m}^{-3}\right)^{\mathrm{b}}$ & $1.239 \times 10^{-4 b}$ \\
\hline$\{2\}$ & $2 L i_{(\text {soln })}^{2+}+S_{8(\text { soln })}^{2-} \leftrightarrows L i_{2} S_{8(\text { solid })}$ & $10^{-20}$ & $\mathrm{Li}_{2} \mathrm{~S}_{8(\text { solid })}$ & $500^{\mathrm{a}}$ & $1.5 \times 10^{-4 c}$ \\
\hline$\{3\}$ & $2 L i_{(\text {soln })}^{2+}+S_{6(\text { soln })}^{2-} \leftrightarrows L i_{2} S_{6(\text { solid })}$ & $10^{-20}$ & $\mathrm{Li}_{2} \mathrm{~S}_{6(\text { solid })}$ & $500^{\mathrm{a}}$ & $1.1 \times 10^{-4 c}$ \\
\hline$\{4\}$ & $2 L i_{(\text {soln })}^{2+}+S_{4(\text { soln })}^{2-} \leftrightarrows L i_{2} S_{4(\text { solid })}$ & $10^{-20}$ & $\mathrm{Li}_{2} \mathrm{~S}_{4(\text { solid })}$ & $500^{\mathrm{a}}$ & $7.5 \times 10^{-5 c}$ \\
\hline$\{5\}$ & $2 L i_{(\text {soln })}^{2+}+S_{2(\text { soln })}^{2-} \leftrightarrows L i_{2} S_{2(\text { solid })}$ & $10^{-9}$ & $\mathrm{Li}_{2} \mathrm{~S}_{2(\text { solid })}$ & $30^{\mathrm{a}}$ & $4.317 \times 10^{-5 b}$ \\
\hline$\{6\}$ & $2 L i_{(\text {soln })}^{2+}+S_{(\text {soln })}^{2-} \leftrightarrows L i_{2} S_{(\text {solid })}$ & $5 \times 10^{-7}$ & $\operatorname{Li}_{2} S_{(\text {solid })}$ & $10^{\mathrm{a}}$ & $2.768 \times 10^{-4 b}$ \\
\hline
\end{tabular}

assumed parameters.

${ }^{\mathrm{b}}$ Taken from Ref. 31.

${ }^{\mathrm{c}}$ Calculated based on the assumed densities.

solutes. The cathode potential is the equilibrium potential and the kinetic overpotential combined, the former depend on the concentration of polysulfides in the electrolyte and the latter being determined from the current balance equation. The total cell potential finally results from the anode potential being related to the concentration of lithium ions at the separator/anode interface.

\section{Methodology: Overall Construction and Governing Equations}

Structural properties of the cathode.-The inter-particular porosity and the carbon mesoporosity before sulfur impregnation are given by Eqs. 1 and 2 respectively

$$
\begin{gathered}
\varepsilon_{1}^{\max }=1-\rho\left(\frac{4 \pi R_{p}^{3}}{3}\right) \\
\varepsilon_{2}^{\max }=N_{p} \rho\left(\frac{4 \pi r_{p}^{3}}{3}\right)
\end{gathered}
$$

where $\rho$ is the number density of the carbon particles and $N_{p}$ is the number of mesopores within each carbon particle.

After $S_{8(\text { solid })}$ impregnation the initial porosities are given by Eqs. 3 and 4 respectively

$$
\begin{gathered}
\varepsilon_{1}^{\text {init }}=\left[1-\rho\left(\frac{4 \pi R_{p}^{3}}{3}\right)\right]\left[1-e k_{1}\left\{S_{8}\right\}\right] \\
\varepsilon_{2}^{\text {init }}=\left[N_{p} \rho\left(\frac{4 \pi r_{p}^{3}}{3}\right)\right]\left[1-e k_{2}\left\{S_{8}\right\}\right]
\end{gathered}
$$

where $e k_{1}\left\{S_{8}\right\}$ and $e k_{2}\left\{S_{8}\right\}$, are the volume fractions of the $S_{8(\text { solid })}$ impregnated.

The maximum carbon surface areas of the inter-particular pores and the mesopores are given by Eqs. 5 and 6 respectively

$$
a_{1}^{\max }=\rho\left(4 \pi R_{p}^{2}\right)
$$

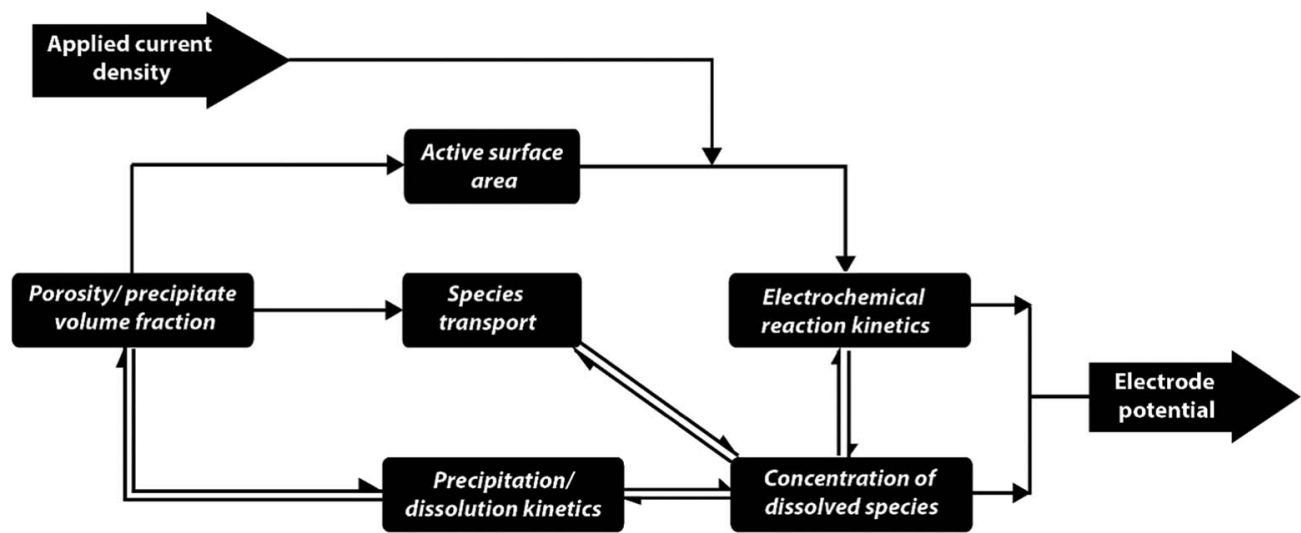

Figure 2. Flow chart of our model. 


$$
a_{2}^{\max }=N_{p} \rho\left(4 \pi r_{p}^{2}\right)
$$

Due to their smaller size, the mesopores have a very high specific surface area and the passivation effect by $S_{8(\text { solid })}$ is considered to be negligible, while the initial surface area is given by

$$
a_{2}^{\text {init }}=a_{2}^{\max }
$$

However, the carbon active surface area of the inter-particular pores is reduced, given by the relation

$$
a_{1}^{i n i t}=a_{1}^{\max }\left[1-\frac{e k_{1}\left\{S_{8}\right\}}{\varepsilon_{1}^{\max }}\right]^{1.5}
$$

Electrochemical reaction kinetics.-The rate of each electrochemical reaction reported in Table I is given by the Butler-Volmer equation

$$
\left(i_{1}\right)_{\langle j\rangle}=n_{\langle j\rangle} q\left[\left(K_{1}^{a}\right)_{\langle j\rangle} \exp \left(\frac{\eta F}{2 R T}\right)-\left(K_{1}^{c}\right)_{\langle j\rangle} \exp \left(-\frac{\eta F}{2 R T}\right)\right]
$$

where $n_{\langle\mathrm{j}\rangle}$ is the absolute number of elementary charges transferred in reaction $\langle\mathrm{j}\rangle, \mathrm{q}=1.602 \times 10^{-19} \mathrm{C}$ is the elementary charge, and $\eta$ is the kinetic overpotential. $K^{a}{ }_{1}$ and $K^{c}{ }_{1}$ are the anodic and cathodic rate constants from transition-state theory

$$
\left(K_{1}^{a}\right)_{\langle j\rangle}=\left(\frac{k T}{h}\right) \kappa A e^{-\left(\frac{E_{B(j\rangle}}{R T}\right)} \prod_{(i)}\left[\frac{\left(c_{1}\right)_{(i)}}{\left(c_{r e f}\right)_{(i)}}\right]^{p_{(i)\langle j\rangle}}
$$

and

$$
\left(K_{1}^{c}\right)_{\langle j\rangle}=\left(\frac{k T}{h}\right) \kappa A e^{-\left(\frac{E_{F(j)}}{R T}\right)} \prod_{(i)}\left[\frac{\left(c_{1}\right)_{(i)}}{\left(c_{r e f}\right)_{(i)}}\right]^{q_{(i)\langle j\rangle}}
$$

where $k$ is the Boltzmann constant, $T$ is the temperature, $h$ is the Planck constant, $\kappa$ is the frequency factor, $A$ is an area factor, $c_{\text {ref }}$ is the reference concentration, and $E_{\mathrm{F}}$ and $E_{\mathrm{B}}$ are the forward and backward activation energies, respectively. The subscript (i) in the Eqs. 10 and 11 corresponds to the species index (Table I), $p_{(i)\langle j\rangle}$ and $q_{(i)\langle j\rangle}$ are the product and reactant coefficients of the species involved in the electrochemical reactions listed in Table I.

The Eqs. 9-11 hold for both the electrochemical reactions in the inter-particular pores and in the mesopores, but all concentration variables must be substituted accordingly.

Chemical reaction rates.-As in previously reported models, ${ }^{31,35-37}$ the chemical reaction rates of the dissolution/ precipitation reactions (Table II) depend on the concentration of dissolved species in the electrolyte, $c_{(i)}$, and the volume fraction of the solid precipitates in the cathode, $\varepsilon_{\{k\}}$. Since the physics are the same for both inter-particular pores and mesopores, the rate equation is given without the subscripts. The rate of a dissolution/precipitation reaction $R_{\{k\}}$ is given by

$$
R_{\{k\}}=k_{\{k\}} \varepsilon_{\{k\}}\left(\prod_{(i)} c_{(i)}^{\gamma_{(i)\{k\}}}-K_{\{k\}}\right)
$$

where $k_{\{\mathrm{k}\}}$ is the chemical rate constant, $K_{\{\mathrm{k}\}}$ is the solubility product and $\gamma_{(\mathrm{i})\{\mathrm{k}\}}$ is the co-efficient of the species involved.

Transport in the electrolyte.-Generally, the electrolytes used in Li-S batteries are highly viscous and the dissolved species concentrations will reach very high values along discharge, thus for the sake of simplicity we assume transport of species in the electrolyte to be diffusive. Apart from the anion of the dissolved lithium salt, the evolution of the concentrations of all the other solutes in the inter-particular pores is given by the mass conservation expression

$$
\frac{\partial\left(c_{1} \varepsilon_{1}\right)}{\partial t}=\frac{\partial}{\partial x}\left[\left(\varepsilon_{1}\right)^{1.5} D\left(\frac{\partial c_{1}}{\partial x}\right)\right]+g_{1}-G_{1}+f
$$

where $\varepsilon_{1}$ is the inter-particular porosity, $c_{1}$ is the dissolved species concentration, $\mathrm{D}$ is the diffusion coefficient, $\mathrm{g}_{1}$ and $\mathrm{G}_{1}$ are the rates of the electrochemical and chemical reactions. The final term $f$ is called the "intra-flux"; accounting for the exchange of dissolved species between inter-particular pores and mesopores. The factor $\varepsilon_{1}^{1.5}$ represents the classical Bruggeman correction to the diffusion coefficient in porous media. ${ }^{28,43}$

A similar equation is used to describe the concentration evolution inside the mesopores, but the global diffusion flux term is removed:

$$
\frac{\partial\left(c_{2} \varepsilon_{2}\right)}{\partial t}=g_{2}-G_{2}-f
$$

The electrochemical reaction source term $\left(\mathrm{g}_{1} / \mathrm{g}_{2}\right)$ for a specific species (i) is given by

$$
g_{(i)}=-a \sum_{\langle j\rangle} \frac{s_{(i)\langle j\rangle} i_{1,\langle j\rangle}}{\nu_{\langle j\rangle} F}
$$

where $a$ is the active surface area and $\mathrm{s}_{(\mathrm{i})(\mathrm{j}\rangle}$ and $v_{(\mathrm{j}\rangle}$ are the coefficients of the species and number of electrons involved, respectively (Table I). by

The chemical reaction source term $\left(\mathrm{G}_{1} / \mathrm{G}_{2}\right)$ for a species (i) is given

$$
G_{(i)}=\sum_{\{k\}} \gamma_{(i)\{k\}} R_{\{k\}}
$$

For the separator the evolution of the concentration is also given by the mass conservation Eq. 13. However, the chemical, electrochemical and intra-flux source terms are not applicable as the separator is assumed to be a homogenous porous medium without any chemical or electrochemical reactions occurring inside.

Intra-flux.-The intra-flux term $f$ used in Eqs. 13 and 14 is a key concept in our multi-scale model. It is featured as "intra-" rather than "inter-" as it describes the exchange of species between the inter-particular pores and mesopores only within the same bin of the discretized cathode (Figure 3).

The intra-flux of a given species within a bin is given by

$$
f=K_{\text {flux }} D\left(c_{2}-c_{1}\right) \Xi\left(\delta_{1}\right)
$$

where $K_{\text {flux }}$ is a rate constant and the "choking function", $\Xi\left(\delta_{1}\right)$, describes the resistance to mass exchange between the inter-particular

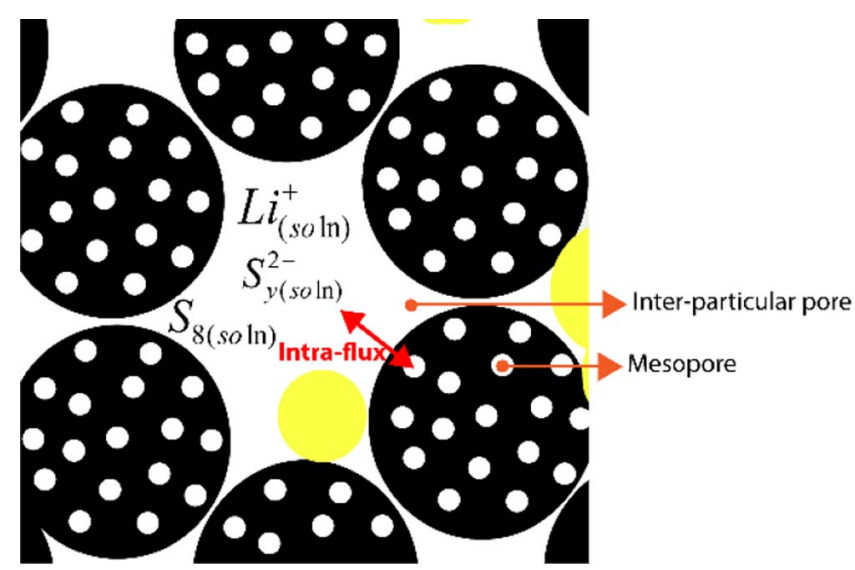

Figure 3. Schematic of the exchange of mass between mesopores and interparticular pores. 
pores and the mesopores:

$$
\Xi\left(\delta_{1}\right)=\frac{1-\operatorname{erf}\left(\frac{\delta_{1}-\delta_{c h o k}}{L_{c h o k}}\right)}{2}
$$

In Eq. 18, erf is the error function, $\delta_{1}$ is the thickness of the $L i_{2} S_{(\text {solid })}$ thin film covering the external surface of the carbon particles, $\delta_{\text {chok }}$ is a characteristic $L i_{2} S_{\text {(solid) }}$ thin film thickness of halved probability of mass exchange, and $L_{\text {chok }}$ is a scaling factor. When $\Xi$ approaches zero, the mesopores become fully choked, forbidding any intra-flux within that bin.

Dynamic viscosity evolution.-The diffusion coefficient $D$ in Eq. 13 is assumed to be affected by the long chain polysulfides generated during discharge, increasing the viscosity of the electrolyte. The diffusion coefficient of a spherical species in a viscous solution is expressed through the Stokes-Einstein relation as

$$
D=\frac{k T}{6 \pi \mu r_{s}}
$$

where $\mu$ is the viscosity and $r_{\mathrm{s}}$ is the radius of the species. For nonspherical species, a correction factor will appear in the denominator, but the relation between diffusion coefficient and viscosity remains as

$$
D \propto \frac{1}{\mu}
$$

Since $S_{8(\text { soln })}$ and $S_{8(s o l n)}^{2-}$ are larger than the solvent molecules and other solutes in the electrolyte, we account for them as suspended particles. The relative viscosity is hence calculated using Einstein's formula for a monodispersed suspension ${ }^{44}$

$$
\frac{\mu}{\mu_{0}}=\frac{1+0.5 \varphi}{(1-\varphi)^{4}}
$$

where $\mu_{0}$ is the viscosity of the pure electrolyte and $\mu$ is the viscosity with suspended particles, whose volume fraction is $\varphi$. We assume that

$$
\varphi=c_{1}\left(\mathrm{~S}_{8}\right) \bar{V}_{\mathrm{S}_{8}}+c_{1}\left(\mathrm{~S}_{8}^{2-}\right) \bar{V}_{\mathrm{S}_{8}^{2-}}
$$

where $\bar{V}_{\mathrm{S}_{8}}$ and $\bar{V}_{\mathrm{S}_{8}^{2-}}$ are the partial molar volumes of $S_{8(\text { soln })}$ and $S_{8(s o l n)}^{2-}$, respectively. While indeed, Eq. 21 neglects the effects of other solutes, the long chain polysulfides can potentially affect the transport of all the solutes in the confined environment of the porous media, especially as the $S_{8(s o l n)}^{2-}$ concentration can be very large and contribute significantly to electrolyte viscosity. There is lack of experimental data on the evolution of electrolyte viscosity during discharge and the contributions of different solutes, but this approach suggests a viable path toward a better understanding.

Active surface area and porosity. - The loss of inter-particular active surface area due to solid sulfur loading is calculated based on a phenomenological expression also adopted by previous models. ${ }^{31,35-37}$ Since we assume that the $\mathrm{Li}_{2} \mathrm{~S}_{\text {solid }}$ film passivates the carbon particle surface, its active surface is calculated based on the film thickness using an electron tunneling probability function modified from a model for $\mathrm{Li}-\mathrm{O}_{2}$ batteries $^{45}$ by some of us

$$
a_{1}=a_{1}^{\max }\left[1-\frac{e_{k 1}\left(\mathrm{~S}_{8}\right)}{\epsilon_{1}^{\max }}\right]^{1.5} \Theta\left(\delta_{1}\right)
$$

where $\Theta$ is the electron tunneling probability function

$$
\Theta\left(\delta_{1}\right)=\frac{1-\operatorname{erf}\left(\frac{\delta_{1}-\delta_{\text {tun }}}{L_{\text {tun }}}\right)}{2}
$$

$\delta_{1}$ comes from Eq. 18, $\delta_{\text {tun }}$ is a threshold thickness at halved electron tunneling probability, and $L_{\text {tun }}$ is a scaling factor.

The passivation effect due to the loaded $S_{8(\text { solid })}$ is neglected, but the losses due to the passivation by the $L i_{2} S_{(\text {solid })}$ film on the internal mesoporous surface and the choking of some mesopores entrances by the film formed over the external particle surface are both included.

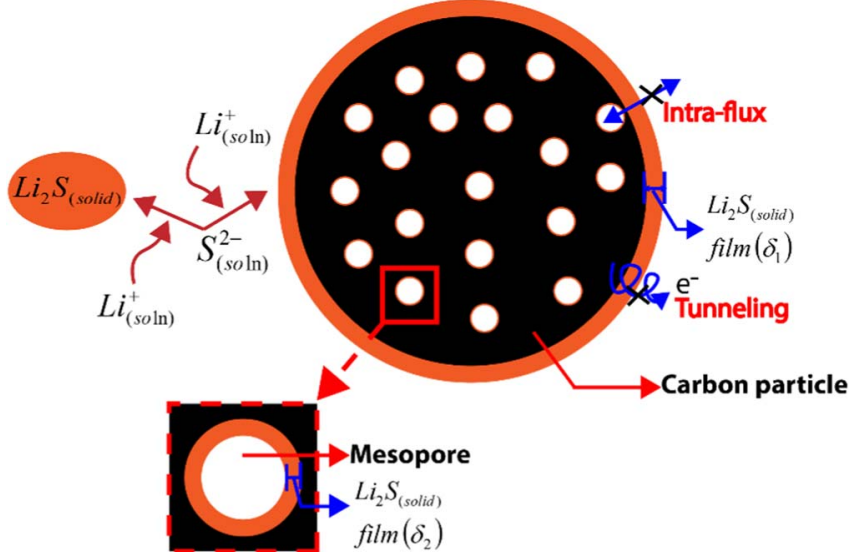

Figure 4. Schematic representation of the $\mathrm{Li}_{2} S_{(s)}$ precipitation routes.

The fraction of mesopores that are not choked are computed using the choking function (Eq. 18).

$$
a_{2}=a_{2}^{\max }\left(\frac{R_{p}-\delta_{2}}{R_{p}}\right)^{2} \Theta\left(\delta_{2}\right) \Xi\left(\delta_{1}\right)
$$

where the term $\left(\frac{R_{p}-\delta_{2}}{R_{p}}\right)^{2}$ characterizes the decrease of the mesoporous surface area (Figure 4).

Similar to previous models, ${ }^{31,35-37}$ the inter-particular porosity and the mesoporosity are evaluated based on the volume fraction of the solid precipitates within the pores. The precipitation rate of a solid precipitate $\{k\}$ in the inter-particular pores within a control volume element $V$ is given by

$$
\frac{d n_{1,\{k\}}}{d t}=\varepsilon_{1} V R_{1,\{k\}}^{\prime}
$$

The volume fraction of $\{\mathrm{k}\}$ is determined from its density, molar mass and amount

$$
e_{k 1}\{k\}(t)=\left(\frac{M_{\{\mathrm{k}\}}}{\rho_{\{\mathrm{k}\}} V}\right) n_{1,\{k\}}(t)=\left(\frac{M_{\{\mathrm{k}\}}}{\rho_{\{\mathrm{k}\}}}\right) \int_{0}^{t} \varepsilon_{1}\left(t^{\prime}\right) R_{1,\{k\}}^{\prime}\left(t^{\prime}\right) d t^{\prime}
$$

Similarly, the evolution in the mesopores is given by

$$
e_{k 2}\{k\}(t)=\left(\frac{M_{\{\mathrm{k}\}}}{\rho_{\{\mathrm{k}\}} V}\right) n_{2,\{k\}}(t)=\left(\frac{M_{\{\mathrm{k}\}}}{\rho_{\{\mathrm{k}\}}}\right) \int_{0}^{t} \varepsilon_{2}\left(t^{\prime}\right) R_{2,\{k\}}^{\prime}\left(t^{\prime}\right) d t^{\prime}
$$

The evolution of the inter-particular porosity and the mesoporosity of the cathode, respectively, follows

$$
\varepsilon_{1}=\varepsilon_{1}^{\max }-\sum_{\{k\}} e_{k 1}\{k\}
$$

and

$$
\varepsilon_{2}=\left[\varepsilon_{2}^{\max }-\sum_{\{k\}} e_{k 2}\{k\}\right] \Xi\left(\delta_{1}\right)
$$

Film thickness. $-L i_{2} S_{(\text {solid })}$ is the primary solid precipitate and the precipitation in the inter-particular pores may occur either through a solution phase route in the bulk electrolyte or a surface-limited thin film route (Figure 4). The volume fraction of the $\mathrm{Li}_{2} \mathrm{~S}_{(\text {solid) }}$ thin film in the inter-particular pores is given by

$$
e_{f 1}\left\{L i_{2} S\right\}(t)=[1-\chi] e_{k 1}\left\{L i_{2} S\right\}(t)
$$

where $\chi$ is the escape function, ${ }^{46}$ the fraction of $L i_{2} S_{(\text {solid })}$ precipitated as particles in the inter-particular pores. Assuming the film to cover the external surface of the carbon particle as a hollow sphere, its thickness 
is given by

$$
\delta_{1}\left\{L i_{2} S\right\}(t)=\left[\frac{3\left(e_{f 1}\left\{L i_{2} S\right\}(t)-\varepsilon_{1}^{\max }+1\right)}{4 \pi \rho}\right]^{\frac{1}{3}}-R_{p}
$$

The total volume fraction of the $L i_{2} S_{(\text {solid })}$ produced in the mesopore is simply the volume fraction of the $L i_{2} S_{(\text {solid })}$ film formed over its internal carbon surface:

$$
e_{f 2}\left\{L i_{2} S\right\}(t)=e_{k 2}\left\{L i_{2} S\right\}(t)
$$

Similarly, the thickness of the $L i_{2} S_{(\text {solid })}$ film formed inside the mesopore is given by

$$
\delta_{2}\left\{L i_{2} S\right\}(t)=r_{p}-\left[\frac{3\left(\varepsilon_{2}^{\max }-e_{f 2}\left\{L i_{2} S\right\}(t)\right)}{4 \pi \rho N_{p}}\right]^{\frac{1}{3}}
$$

Current balance.-The sum of the faradaic current densities of all the electrochemical reactions is set equal to the applied current density, $\mathrm{I}_{\mathrm{G}}$ (we neglect the double layer effect ${ }^{47}$

$$
I_{G}=-\sum_{\langle j\rangle} \int_{\mathrm{B}}^{\mathrm{C}}\left[a_{1}\left(i_{1}\right)_{\langle j\rangle}+a_{2}\left(i_{2}\right)_{\langle j\rangle}\right] d x
$$

where the minus sign emerges as the anodic direction is positive in Eq. 19.

Cell voltage.-The general form of the equilibrium potential expression for any electrochemical reaction is

$$
U_{\langle j\rangle}=U_{\langle j\rangle}^{\theta}-\frac{R T}{n_{\langle j\rangle} F} \sum_{(i)} s_{(i)\langle j\rangle} \ln \left[\overline{\left(c_{1}\right)_{(i)}\left(f_{1}\right)_{(i)}}\right]
$$

where $U_{\langle j\rangle}^{\theta}$ is the standard potential of a electrochemical reaction $\langle\mathrm{j}\rangle$, $\left(c_{1}\right)_{(i)}$ is the avearge concentration of a species (i) and $\left(f_{1}\right)_{(i)}$ is its activity coefficient, the bar denotes averaged values.

As the concentration of $\mathrm{Li}_{(\text {soln })}^{+}$evolves significantly in Li-S batteries the anode equilibrium potential is hence determined using Nernst's equation for lithium metal oxidation

$$
U_{\langle 1\rangle}=\frac{R T}{F} \ln \left[\overline{c_{1}\left(L i^{+}\right) f_{1}\left(L i^{+}\right)}\right]
$$

Similarly, the cathode equilibrium potential is calculated based on the $S_{2(\text { soln })}^{2-} / S_{(\text {soln })}^{2-}$ reduction reaction, as it is the dominant reaction in most parts of the discharge event as suggested by Kumaresan et al., ${ }^{31}$

$$
U_{\langle 6\rangle}=U_{\langle 6\rangle}^{\theta}+\frac{R T}{2 F} \ln \left\{\frac{\overline{c_{1}\left(\mathrm{~S}_{2}{ }^{2-}\right) f_{1}\left(\mathrm{~S}_{2}{ }^{2-}\right)}}{\left[\overline{c_{1}\left(\mathrm{~S}^{2-}\right) f_{1}\left(\mathrm{~S}^{2-}\right)}\right]^{2}}\right\}^{2}
$$

The cell voltage is the difference between the cathode and anode equilibrium potentials, plus the cathode overpotential

$$
U_{\text {cell }}=U_{\langle 6\rangle}-U_{\langle 1\rangle}+\eta
$$

The cell potential drop due to electrolyte resistance during the high plateau and the intermediate stage between the discharge plateaus has been found to be more significant than the activation overpotential. ${ }^{48}$ However, EIS studies carried out by Deng et al., ${ }^{49}$ showed that the charge transfer resistance, corresponding to the activation overpotential, and the surface film resistance, are much larger than electrolyte resistance throughout the discharge event. This suggests that the cell potential can be limited by charge transfer and surface resistance even when the electrolyte conductivity is adequate.

Therefore, it is reasonable to assume that the cell potential drop is dictated by the cathode overpotential and as the latter is determined by inverting the overall current balance equation it also includes the mass transport and surface passivation effects, via our model's strong coupling of these phenomena.
Table III. General parameters of the simulated Li-S cell.

\begin{tabular}{lccc} 
Parameter name & Parameter symbol & Value & Unit \\
\hline Cathode thickness & $L_{\text {cat }}$ & $40^{\mathrm{a}}$ & $\mu m$ \\
Separator thickness & $L_{\text {sep }}$ & $20^{\mathrm{a}}$ & $\mu m$ \\
Separator porosity & $\varepsilon_{s e p}$ & $50^{\mathrm{a}}$ & $\%$ \\
Particle radius & $R_{p}$ & $100^{\mathrm{b}}$ & $\mathrm{nm}$ \\
Pore radius & $r_{p}$ & $3^{\mathrm{b}}$ & $\mathrm{nm}$ \\
Particle number density & $\rho$ & $1.79 \times 10^{20 \mathrm{c}}$ & $\mathrm{m}^{-3}$ \\
Number pores per particle & $N_{p}$ & $22222^{\mathrm{c}}$ & - \\
Number of cathode bins & $P$ & $10^{\mathrm{a}}$ & - \\
Number of separator bins & $Q$ & $5^{\mathrm{a}}$ & - \\
Escape function & $\chi$ & $0.5^{\mathrm{a}}$ & - \\
Choking thickness & $\delta_{c h o k}$ & $3^{\mathrm{a}}$ & $\mathrm{nm}$ \\
Choking extension & $L_{c h o k}$ & $4^{\mathrm{a}}$ & $\mathrm{nm}$ \\
Tunneling threshold & $\delta_{t u n}$ & $5^{\mathrm{a}}$ & $\mathrm{nm}$ \\
Scaling factor tunneling function & $L_{t u n}$ & $2.5^{\mathrm{a}}$ & $\mathrm{nm}$
\end{tabular}

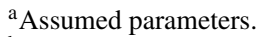

${ }^{\mathrm{b}}$ Taken from the TEM image in Ref. 40.

${ }^{\mathrm{c}}$ Calculated based on the assumed inter-particular porosity and mesoporosity.
}

Computational implementation.-The model was implemented in the in-house MS LIBER-T package coded in Matlab, ${ }^{\mathrm{i}}$ similar to our previously developed computational frameworks for fuel cells ${ }^{50}$ and Li- $\mathrm{O}_{2}$ batteries. ${ }^{45}$ The coupled partial/ordinary differential equations were solved using the finite volume method (cf. Appendix).

All simulations were carried out on a PC equipped with 43.30 $\mathrm{GHz}$ processors Intel core $\mathrm{i5}-4590$ with a typical simulation time of 1.5 to 2 days for a full polarization curve.

The discharge simulations are stopped when either one of these conditions is satisfied:

1. all the solvated sulfur species get completely reduced to $S_{(\text {soln })}^{2-}$ in which case the discharge capacity equals the theoretical capacity;

2. a clogging of pores due to $L i_{2} S_{(\text {solid) }}$ precipitation prevents the transport of active species through the cathode and cause the loss of active surface area;

3. a complete passivation by the $L i_{2} S_{(\text {solid })}$ thin film, defined as a thickness beyond the electron tunneling threshold.

Physical model.-A cathode with $70 \%$ porosity (Table III) is considered as a reference case where the areal loading of sulfur is 2.48 $\mathrm{mg} . \mathrm{cm}^{-2}$ and the inter-particular porosity constitutes $25 \%$ of the volume, whereas the mesoporosity accounts for $45 \%$. The $\mathrm{C} / \mathrm{S}$ volume ratio is $1: 1.70 \%$ of the total volume of the impregnated $S_{8(\text { solid })}$ exists inside the mesopores.

\section{Results and Discussion}

A systematic study of the effects of the battery operation and $\mathrm{C} / \mathrm{S}$ microstructural properties on the discharge is presented in this section. Only those parameters whose effects are being investigated are changed for the simulations reported in each subsection. This way it is possible to track the unique roles of several experimentally modifiable parameters single-handedly, paving the way for a rational design of more performant Li-S cells in general and C/S cathodes in particular.

Rate capability.-The rate capability of the reference cathode microstructure is investigated by simulating discharge using three different current densities: 0.5, 1.0 and $1.5 \mathrm{~mA} . \mathrm{cm}^{-2}$ (Figure 5).

The latter part of the discharge potential decrease as the current density increases, due to the increase in the activation polarization, and also the final discharge capacities decrease, all consistent with 


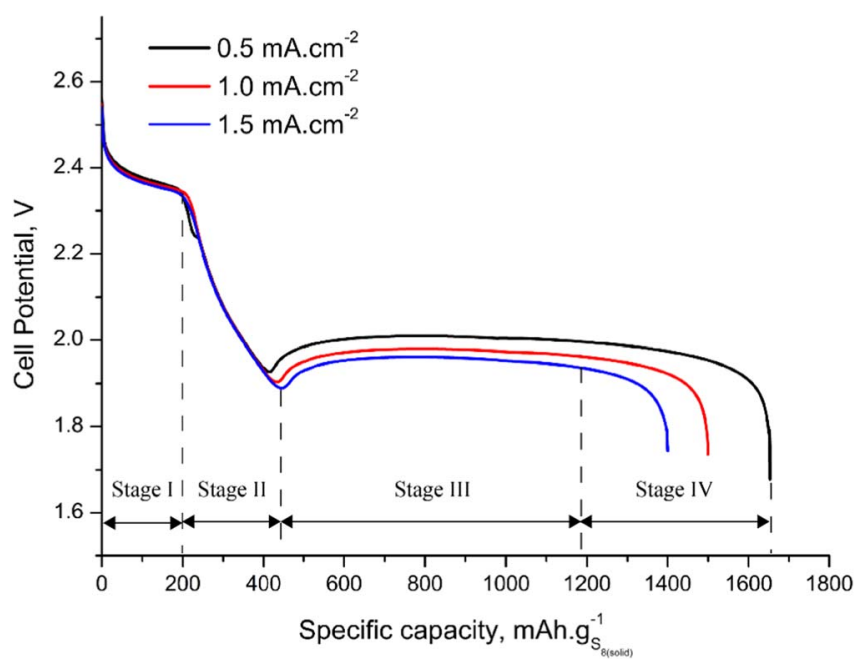

Figure 5. Calculated discharge profiles at current densities $0.5,1.0$ and $1.5 \mathrm{~mA} . \mathrm{cm}^{-2}$ experimental observations. ${ }^{40-42}$ In principle, the equilibrium potential of the cathode can be calculated based on anyone of the reduction reactions (Table I). While, the simulated discharge profiles based on different reduction reactions will have similar characteristics, the corresponding cell potential values may vary. This is mainly due to the reduction reactions that take place during the high plateau stage of our discharge simulations become inactive during the low plateau stage (Figures 6c, 6d), which is physically consistent since the operating potential becomes lower than their reduction potentials.

The predicted total discharge capacities are larger than those reported experimentally - mainly due to the neglect of phenomena such as improper electron wiring of the porous carbon matrix, chemical reactions of polysulfides with the lithium metal anode, and active surface area and porosity losses due to presence of a binder. Neglecting such phenomena, however, allows us to focus on the understanding of carbon microstructure design parameters' impact on the cell performance - and resolving these for the different parts of the discharge event. In more detail, each discharge profile consists of four stages:

- Stage I corresponds to the first plateau of the discharge, when the concentrations of $S_{8(s o l n)}$ and $S_{y(s o l n)}^{2-}$ remain relatively constant (Figures 6a, 6b), due to a steady dissolution of $S_{8(\text { solid })}$ and a subsequent reduction of $S_{8(s o l n)}$ to shorter chain polysulfides;

(b)

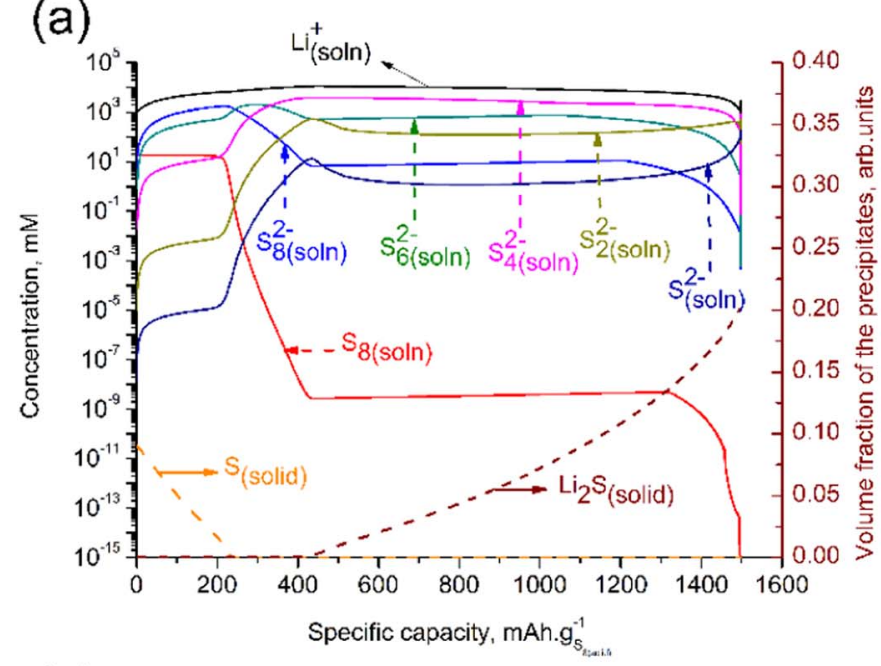

(c)

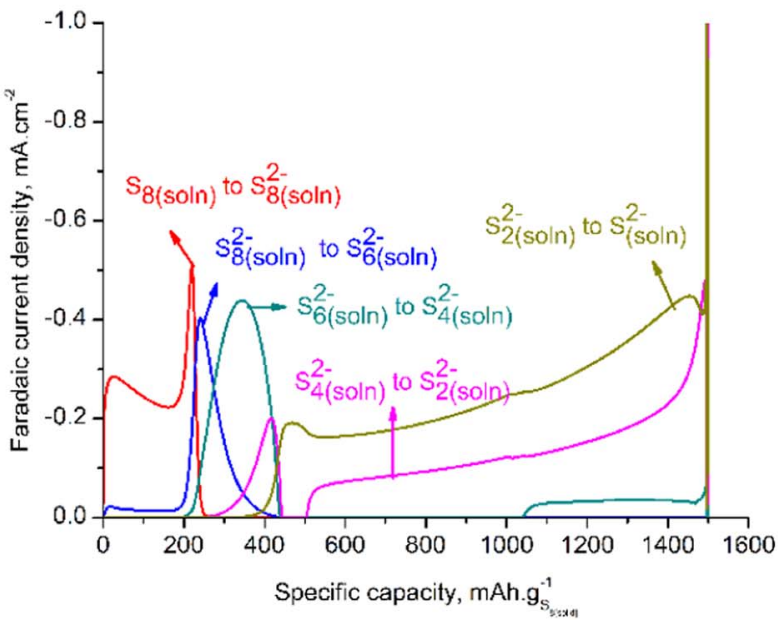

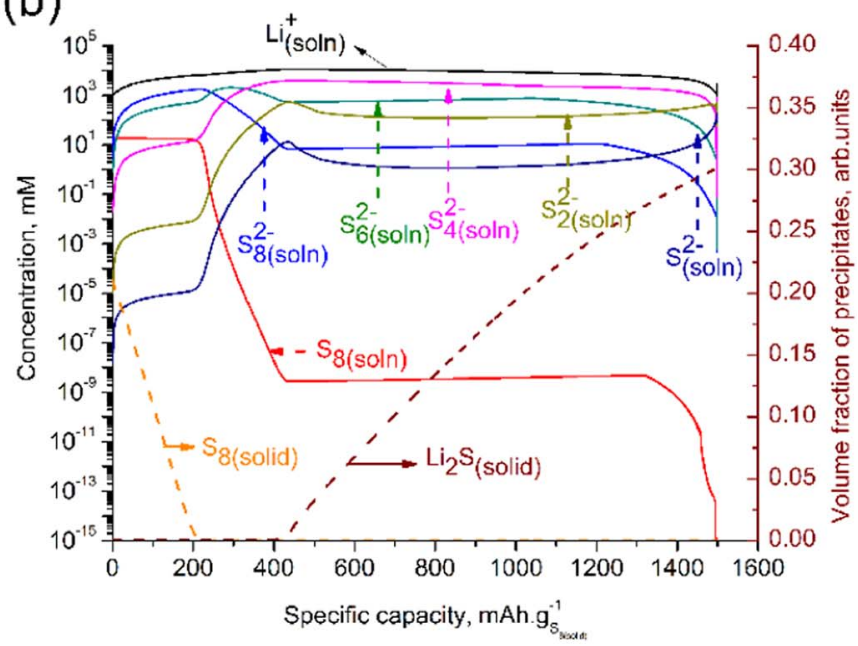

(d)

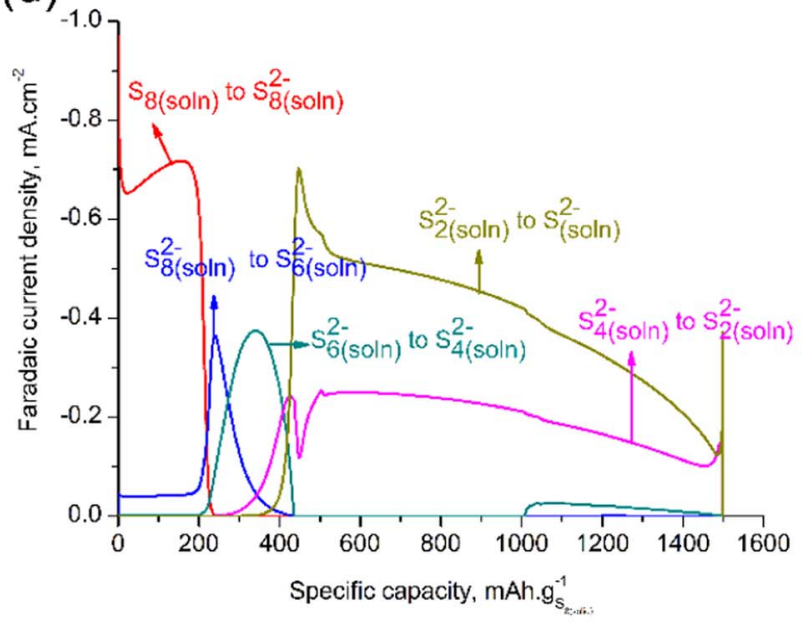

Figure 6. Evolution of concentration of species (solid lines) and volume fractions of the solid precipitates (dashed lines) for a discharge at $1.0 \mathrm{~mA} . \mathrm{cm}^{-2}$ in: (a) the inter-particular pores, and (b) the mesopores. faradaic current densities for different electrochemical reactions in: (c) the inter-particular pores, and (d) the mesopores. 
(a)

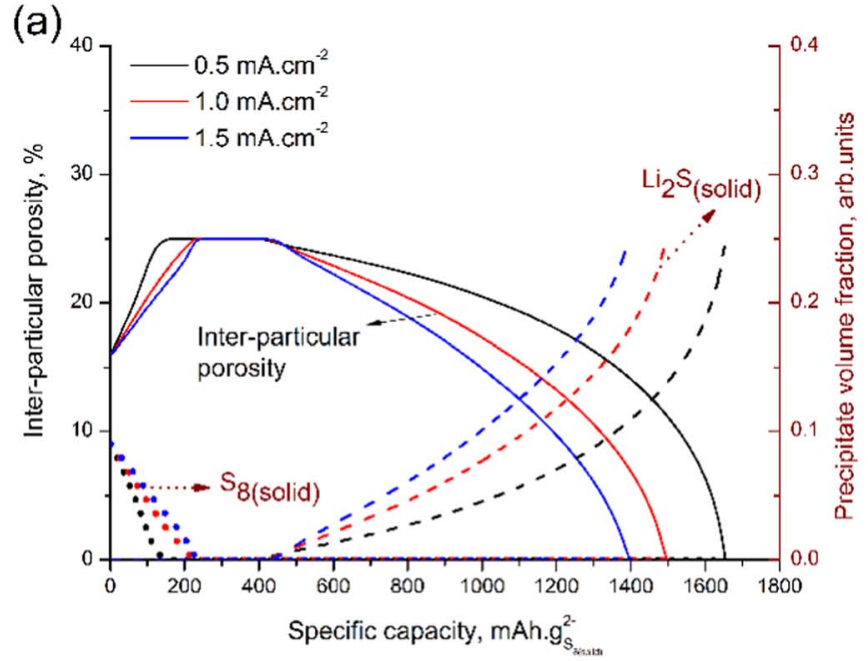

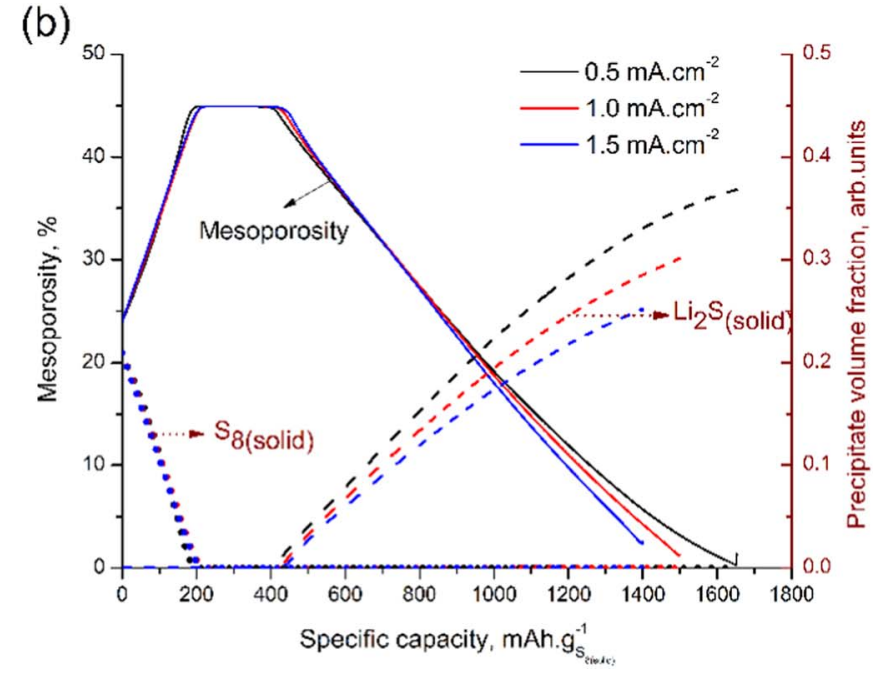

Figure 7. Evolution of porosities and volume fractions of the solid precipitate in: (a) the inter-particular pores, and (b) the mesopores, for the cathode bin closest to the separator.

- Stage II begins after the complete dissolution of $S_{8(\text { solid })}$ where the electrochemical reactions $\langle 2\rangle$ to $\langle 4\rangle$ (Table I) become dominant, leading to the consumption of long chain polysulfides and an increase in the short chain polysulfide concentrations (Figures 7c, 7d). The Stage II discharge potential decreases continuously until it reaches a local minimum when $L i_{(s o l n)}^{+}$and $S_{(s o l n)}^{2-}$ become super-saturated. At this point the nucleation of $\mathrm{Li}_{2} S_{(\text {solid })}$ will start;

- In Stage III the electrochemical reactions $\langle 5\rangle$ and $\langle 6\rangle$ are dominant, but the concentrations of $S_{(\text {soln })}^{2-}$ and $S_{(\text {soln })}^{2-}$ remain relatively constant due to the precipitation of $L i_{2} S_{\text {(solid })}$;

- Finally, Stage IV corresponds to loss of active surface area and porosity in the cathode.

These calculated concentration profiles are almost consistent to those observed in the Ref. 31. The predicted solid species evolution during discharge is also consistent with the crystalline in situ XRD study ${ }^{51}$ which suggest that reaction mechanisms in our model are reasonable.

During discharge, the total concentration of polysulfides will reach a very high value $(\approx 4.8 \mathrm{M})$, but the lithium ion concentration will be more than twice this value. Since the production and consumption rate of electrons in the anode and the cathode, respectively, are identical, the amount of positive and negative charges produced in the cell should also be identical. Even though our model does not have any constraints for electroneutrality, the charge difference between the lithium ions and polysulfide ions minus the initial lithium salt anions is found to be negligible for the complete cell.

At the end of discharge the $L i_{2} S_{(\text {solid })}$ film thickness still allows for electron tunneling, but the inter-particular porosity of the cathode bin closest to the separator falls to zero due to clogging by $L i_{2} S_{(\text {solid) }}$ (Figure 7a).

The discharge capacities are lower than the theoretical capacity for all the three current densities due to the fact that some of the potentially electrochemically active solutes remain blocked in the separator at the end of discharge (Figure 8), and as the clogging is faster during faster discharge, the discharge capacities decrease more upon increased current density. While the lack of accurately determined parameters limits the predictive power the suggested capacity limiting mechanism -the clogging of inter-particular pores in the cathode region closest to the separator -has been identified experimentally. ${ }^{42}$ Hence our model is capable of making qualitative predictions about such cathode micro-structural effects on the discharge performance. The decrease in mesoporosity is larger than the increase in $\mathrm{Li}_{2} S_{(\text {solid) }}$ volume fraction (Figure 7b), with additional losses caused due to the choking of mesopore entrances.

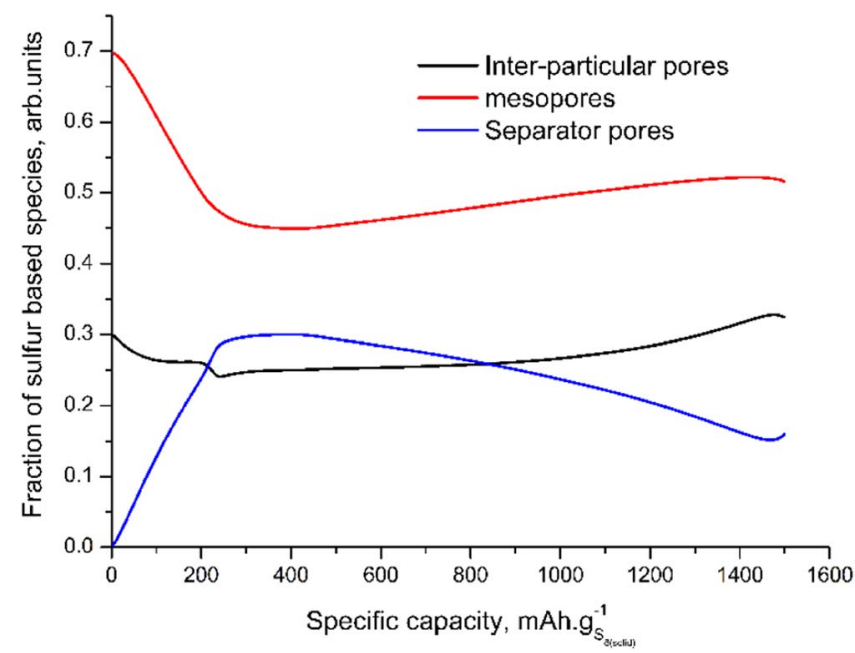

Figure 8. Evolution of the fractions of all the sulfur-based species, precipitates and dissolved, residing at different porous regions for a discharge at $1.0 \mathrm{~mA} . \mathrm{cm}^{-2}$.

Impact of porosity.-The discharge dependence on porosity is simulated by using different $\mathrm{C} / \mathrm{S}$ cathodes

The C/S volume ratio is 1:1 for all three configurations, while the sulfur loading is reduced as the porosity is increased (Table IV). The mesoporosity is increased by increasing the number of mesopores per particle, while the inter-particular porosity is increased by decreasing

Table IV. Sulfur loadings for the three configurations with different carbon porosities.

\begin{tabular}{|c|c|c|c|}
\hline Maximum carbon porosity & $\begin{array}{l}\text { Particle } \\
\text { number } \\
\text { density }\left(\mathrm{m}^{-3}\right)\end{array}$ & $\begin{array}{l}\text { Number of } \\
\text { pores per } \\
\text { particle }\end{array}$ & $\begin{array}{l}\text { Areal } \boldsymbol{S}_{8(\text { solid })} \\
\text { Loading } \\
\left(\mathrm{mg} . \mathrm{cm}^{-2}\right)\end{array}$ \\
\hline $\begin{array}{l}\text { Inter-particular }=25 \% \\
\text { Meso }=45 \% \text { (Reference) }\end{array}$ & $1.79 \times 10^{20}$ & 22222 & 2.48 \\
\hline $\begin{array}{l}\text { Inter-particular }=25 \% \\
\text { Meso }=55 \%\end{array}$ & $1.79 \times 10^{20}$ & 27170 & 1.65 \\
\hline Inter-particular $=35 \%$ & $1.55 \times 10^{20}$ & 25630 & 1.65 \\
\hline
\end{tabular}




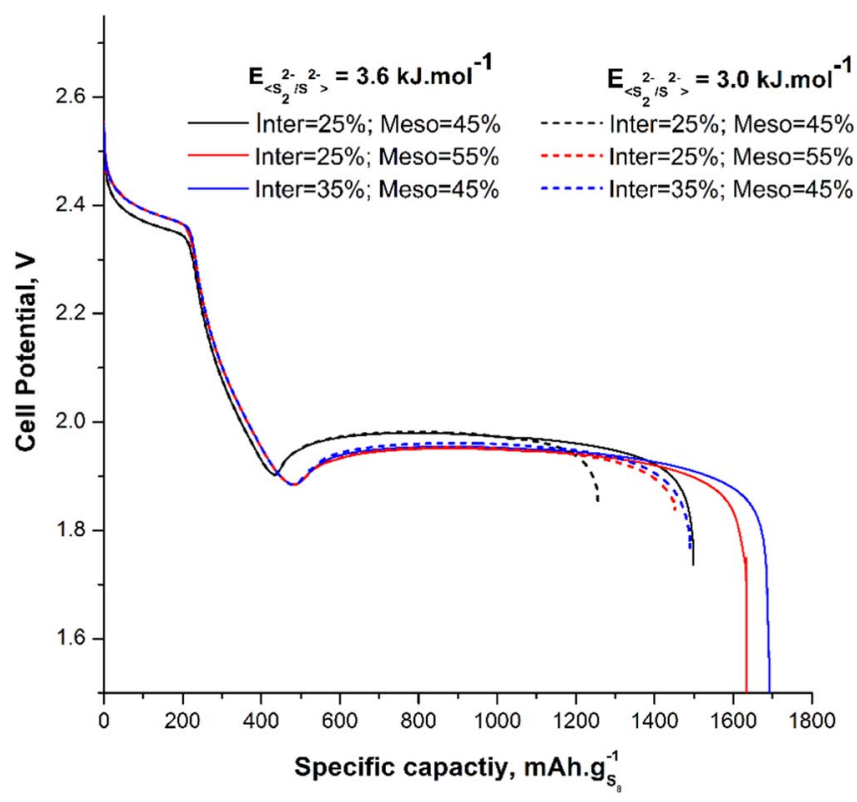

Figure 9. Simulated discharge profiles at $1.0 \mathrm{~mA} . \mathrm{cm}^{-2}$ for the three cathode configurations with $E_{\left\langle S_{2}^{2-} / S^{2-}\right\rangle}=3.6 \mathrm{~kJ}^{2} \mathrm{~mol}^{-1}$ (solid lines) and $E_{\left\langle S_{2}^{2-} / S^{2-}\right\rangle}=$ $3.0 \mathrm{~kJ} \cdot \mathrm{mol}^{-1}$ (dashed lines).

the particle number density and in all the cathodes $70 \%$ of the total impregnated sulfur volume exists in the mesopores.

The calculated discharge capacities are shown to be limited by the clogging of inter-particular pores closest to the separator by $\mathrm{Li}_{2} \mathrm{~S}_{(\text {solid })}$. Therefore to check the reproducibility of the predicted trends, discharge simulation of different cathodes are repeated for two different activation energies corresponding to $S_{2(\text { soln })}^{2-} / S_{(\text {soln })}^{2-}$ reduction reaction $\left(E_{\left\langle S_{2}^{2-} / S^{2-}\right\rangle}\right)$.

The $S_{2(\text { soln })}^{2-} / S_{(s o l n)}^{2-}$ reduction reaction is faster when the activation energy is low $\left(E_{\left\langle S_{2}^{2-} / S^{2-}\right\rangle}=3.0 \mathrm{~kJ} \cdot \mathrm{mol}^{-1}\right)$. Therefore, the discharge capacities of all the cathodes decrease when $E_{\left\langle S_{2}^{2-} / S^{2-}\right\rangle}$ is decreased (Figure 9), due to faster precipitation of $\mathrm{Li}_{2} \mathrm{~S}_{(\text {solid })}$ and earlier clogging of inter-particular pores closest to the separator (Figure 10a).

(a)

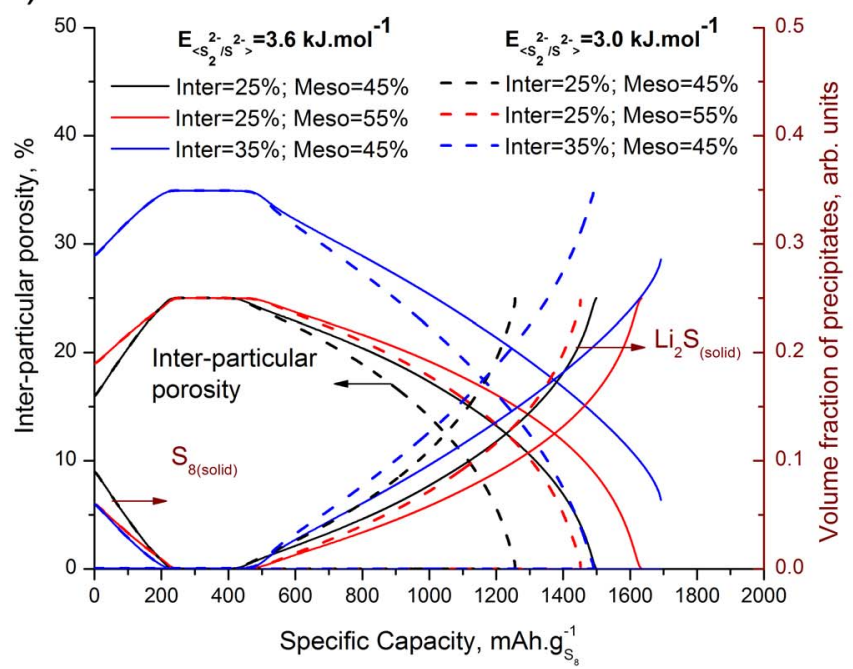

In general, the cathode surface area increases as the mesoporosity increases, which facilitates better active material utilization and hence, as expected, the discharge capacity increases. However, surprisingly, the increase in discharge capacity is slightly pronounced for the cathode with $35 \%$ maximum inter-particular porosity despite its surface area being the lowest among three due its low particle number density (Table IV). The slight increase in the discharge capacity is achieved through its large transport path for the soluble active species, thereby facilitating better access to the carbon surface throughout the cathode. This effect is more pronounced for the discharge curve simulated using high activation energy $\left(E_{\left\langle S_{2}^{2-} / S^{2-}\right\rangle}=3.6 \mathrm{~kJ} \cdot \mathrm{mol}^{-1}\right)$. Under such slow $S_{2(\text { soln })}^{2-} / S_{(\text {soln })}^{2-}$ reduction kinetics, the active species possess ample time to get transported across the cathode. Therefore, unlike the other two cathodes, with $25 \%$ maximum inter-particular porosity, the electrochemical and precipitation reactions take place isotropically in this cathode. This way the inter-particular porous network does not get clogged (Figures 10a and 10b), facilitating the active species access to the entire carbon surface, resulting in a complete utilization.

Impact of particle and pore sizes.-The impact of carbon particle and pore sizes on the discharge performance and its sensitivity to the two different escape functions $(\chi)$ were investigated. The calculated discharge capacities are only slightly decreased by increasing the carbon particle and mesopore sizes (Figure 11) for the case of $\chi=$ 0.5 , the value used in the rate capability analysis. Even though, their corresponding discharge capacities are almost similar, they are limited due to different physical reasons.

Due to the low particle number density, the inter-particular surface area is low for the cathode with larger particles, (Table V), why the $\mathrm{Li}_{2} \mathrm{~S}_{(\text {solid) }}$ film thickness grows at a faster rate (Figure 12), producing an earlier choking of the mesopores with some unutilized active species trapped inside and hence a slightly lowered discharge capacity. However, for the case $\chi=0.3,70 \%$ of the $L i_{2} S_{(\text {solid })}$ precipitates as a thin film, causing a rapid growth of its thickness in the cathode with larger particles, producing a much earlier choking of mesopores and a substantial decrease in the discharge capacity. The potential at the latter part of the discharge decreases for the cathode with large particles which is caused due to the larger passivation effect produce by the thick $L i_{2} S_{(\text {solid })}$ film.

The discharge capacities of the cathodes with smaller particles $(100 \mathrm{~nm})$, remain unchanged for two different escape functions, since

(b)

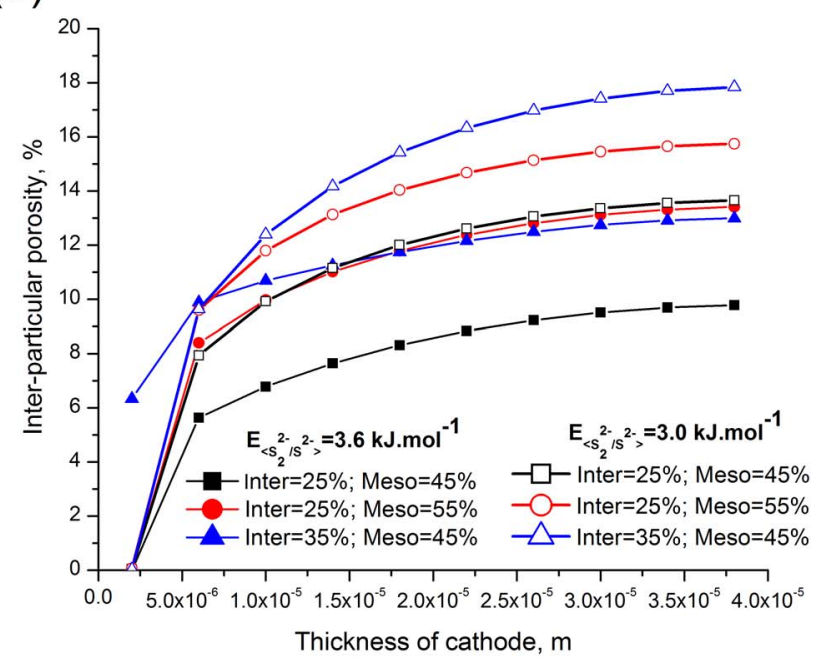

Figure 10. (a) The evolution of the inter-particular porosities and the volume fractions of $S_{8(\text { solid })}$ and $\mathrm{Li}_{2} S_{(\text {solid })}$ in the inter-particular pores, solid lines correspond to $E_{\left\langle S_{2}^{2-} / S^{2-}\right\rangle}=3.6 \mathrm{~kJ}^{-\mathrm{mol}^{-1}}$ and dashed lines correspond to $E_{\left\langle S_{2}^{2-} / S^{2-}\right\rangle}=3.0 \mathrm{~kJ} \cdot \mathrm{mol}^{-1}$ and (b) the distribution of inter-particular porosity along the cathode thickness at the end of discharge, solid points correspond to $E_{\left\langle S_{2}^{2-} / S^{2-}\right\rangle}=3.6 \mathrm{~kJ}^{-\mathrm{mol}^{-1}}$ and hollow points correspond to $E_{\left\langle S_{2}^{2-} / S^{2-}\right\rangle}=3.6 \mathrm{~kJ} . \mathrm{mol}{ }^{-1}$. 


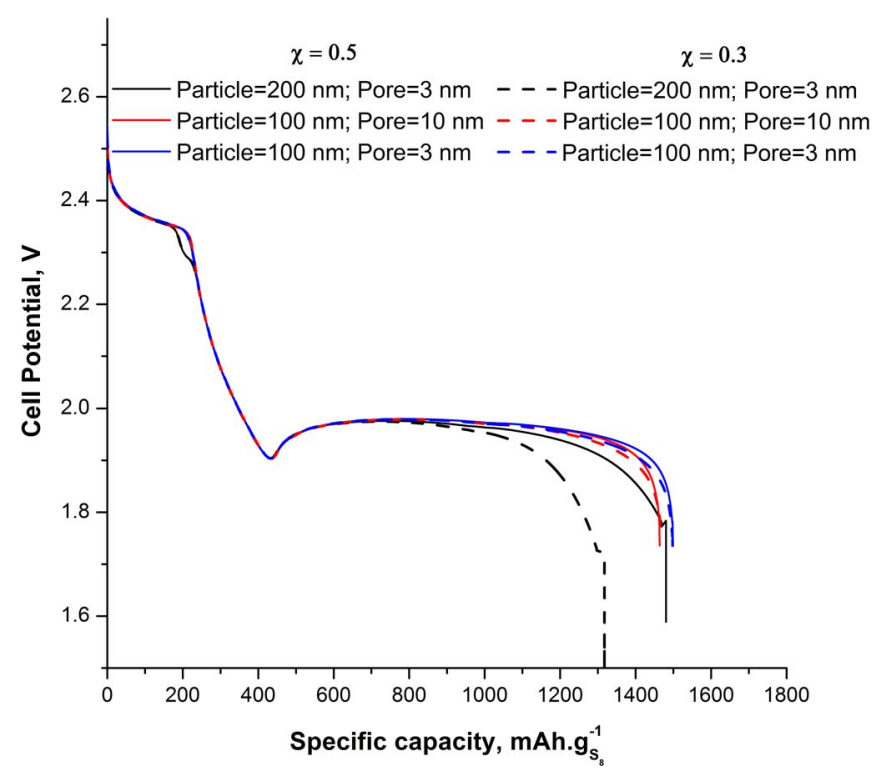

Figure 11. Simulated discharge profiles for cathodes with different particle and pore sizes discharged at $1.0 \mathrm{~mA} . \mathrm{cm}^{-2}$ discharged at $1.0 \mathrm{~mA} . \mathrm{cm}^{-2}$ with $\chi=0.5$ (solid lines) and $\chi=0.3$ (dashed lines).

Table V. Parameters values used for the simulated cathodes containing different particle and pore sizes.

\begin{tabular}{lll}
$\begin{array}{l}\text { Radius of the carbon } \\
\text { particle and the } \\
\text { mesopore in them }\end{array}$ & $\begin{array}{l}\text { Particle number } \\
\text { density }\left(\mathrm{m}^{-3}\right)\end{array}$ & $\begin{array}{l}\text { Number of mesopores } \\
\text { per carbon particle }\end{array}$ \\
\hline $\begin{array}{l}\text { Particle }=100 \mathrm{~nm} \\
\begin{array}{l}\text { Pore }=3 \mathrm{~nm} \\
\text { Reference })\end{array}\end{array}$ & $1.79 \times 10^{20} \mathrm{~m}^{-3}$ & 22222 \\
$\begin{array}{l}\text { Particle }=100 \mathrm{~nm} \\
\text { Pore }=10 \mathrm{~nm}\end{array}$ & $1.79 \times 10^{20} \mathrm{~m}^{-3}$ & 600 \\
$\begin{array}{l}\text { Particle }=200 \mathrm{~nm} \\
\text { Pore }=3 \mathrm{~nm}\end{array}$ & $2.24 \times 10^{19} \mathrm{~m}^{-3}$ & 177778 \\
\end{tabular}

(a)

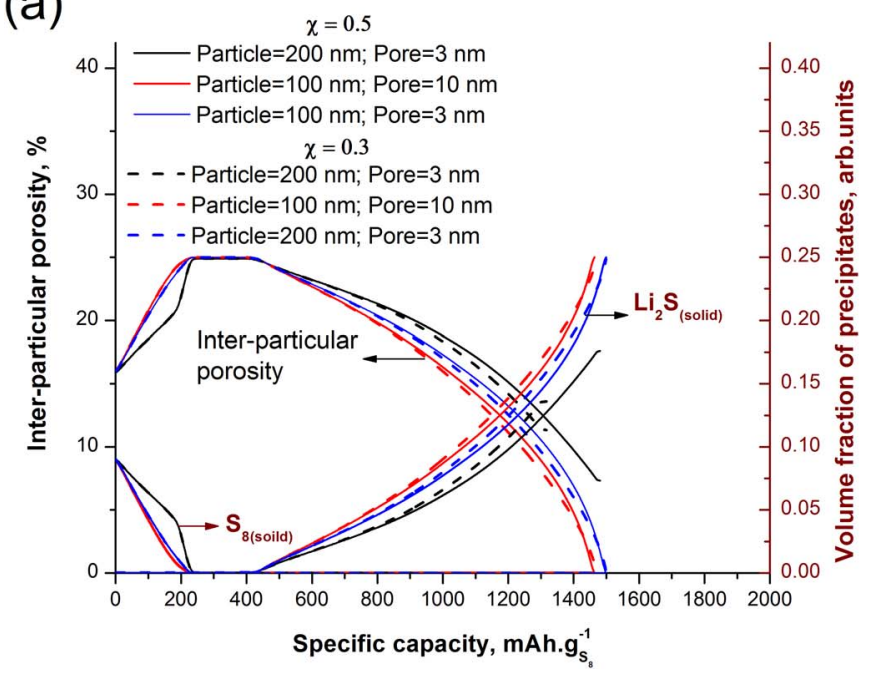

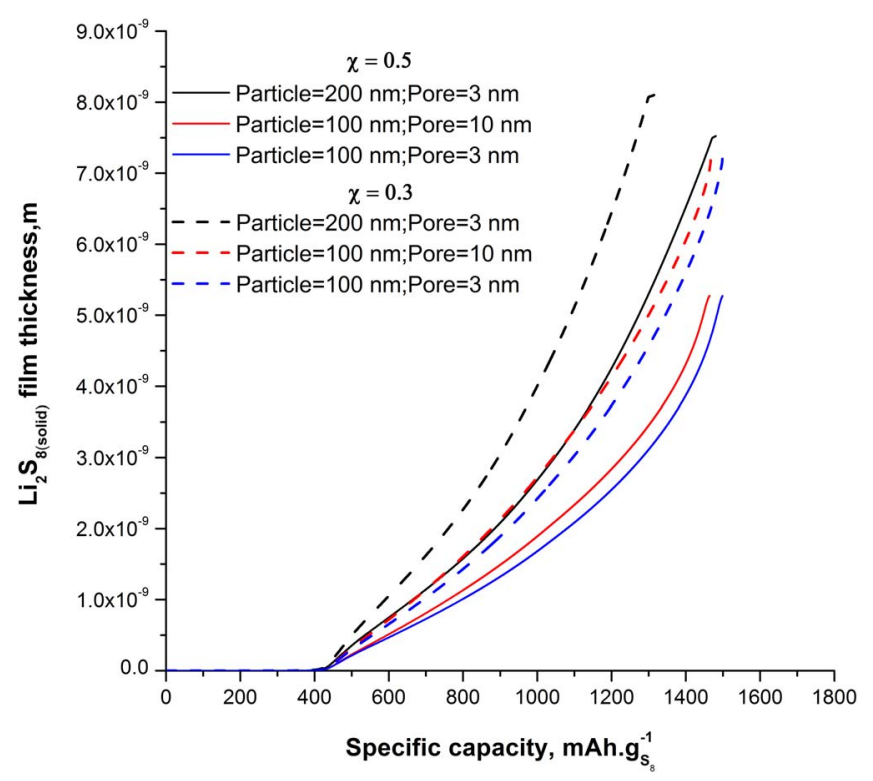

Figure 12. The growth of the $\mathrm{Li}_{2} S_{(\text {solid) }}$ film thickness in the inter-particular pores for $\chi=0.5$ (solid lines) and $\chi=0.3$ (dashed lines).

their capacities are mainly affected by the clogging of inter-particular pores closest to the separator (Figure 13a). $L i_{2} S_{(\text {solid) }}$ film thicknesses of the cathodes with smaller particles grow faster for the case $\chi$ $=0.3$. However, the thickness at the end of discharge are slightly thinner than the threshold thickness necessary to cause the complete choking of the mesopores. The mesoporous surface area decreases when the mesopore sizes are increased, thus the extent of electrochemical and subsequent precipitation reactions taking place inside are decreased along the discharge. Therefore, the $L i_{2} S_{(\text {solid })}$ precipitates at a faster rate in the inter-particular pores of the cathode with large mesopores, causing the inter-particular pores to clog earlier and slightly decreasing the discharge capacity compared to that of the cathode with small particles and mesopores (Figure 11). This result suggests that the accumulation of $\mathrm{Li}_{2} S_{(\text {solid })}$ can be decreased by tailoring the microstructural parameters to produce large mesoporous surface.

(b)

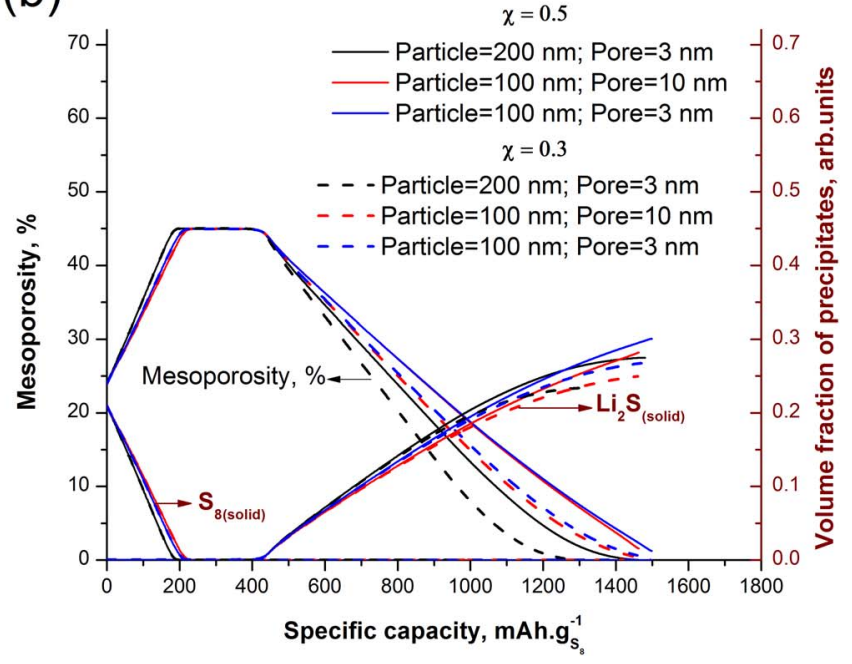

Figure 13. Calculated evolution of the porosities and the volume fractions of $S_{8(\text { solid) }}$ and $\mathrm{Li}_{2} S_{(\text {solid) }}$ in the (a) inter-particular pores, and (b) mesopores of the carbon particles, both for the cathode bin closest to the separator. Solid lines correspond to $\chi=0.5$ and dashed lines correspond to $\chi=0.3$. 


\section{Table VI. Areal sulfur loadings of the cathodes with different C/S composite structure}

\begin{tabular}{ll} 
C/S ratio & Areal $S_{8(\text { solid })}$ loading \\
\hline $1: 1.33$ & $3.30 \mathrm{mg} \cdot \mathrm{cm}^{-2}$ \\
$1: 1$ (Reference) & $2.48 \mathrm{mg} \cdot \mathrm{cm}^{-2}$ \\
$1: 0.67$ & $1.66 \mathrm{mg} \cdot \mathrm{cm}^{-2}$
\end{tabular}

Impact of $\boldsymbol{C} / \mathbf{S}$ ratio.-We simulate the discharge profiles of the cathodes with different $\mathrm{C} / \mathrm{S}$ volume ratios (Table VI) using the same current density, why the C-rate "automatically" increases as the volume fraction $S_{8(\text { solid })}$ is decreased, causing the potential in the latter part of the discharge curve to decrease due to activation polarization (Figure 14). The sensitivity of the $E_{\left\langle S_{2}^{2-} / S^{2-}\right\rangle}\left(=3.6\right.$ and $\left.3.0 \mathrm{~kJ} . \mathrm{mole}{ }^{-1}\right)$ is also tested for the cathodes with different $S_{8(\text { solid })}$ loadings. Although, the capacities of all the cathodes decrease when $E_{\left\langle S_{2}^{2-} / S^{2-}\right\rangle}$ is decreased, the predicted discharge capacity trends for different $S_{8(\text { solid })}$ loadings remain unchanged.

The $S_{8(\text { solid })}$ dissolution rate increases when its volume fraction is increased (Figures 15a and 15b), producing a large amount of soluble polysulfides in the electrolyte and thereby a faster precipitation of $\mathrm{Li}_{2} \mathrm{~S}_{(\text {solid })}$ in the inter-particular pores and mesopores. The calculated discharge capacities decrease for increased $S_{8(\text { solid })}$ loadings (Figure 14) due to an earlier clogging of the inter-particular pores and choking of the mesopores. The calculated discharge capacity trends qualitatively resemble the experimentally observed trends. $^{52}$

\section{Conclusions}

Our comprehensive multi-scale model allows to investigate the effects of practical and experimentally modifiable operation and C/S microstructure properties on the discharge performance. The analysis of the calculated results reveal the physical reasons that limit the discharge capacities. The results qualitatively agree with the experimentally observed trends for example, the discharge capacities decrease when applied current density ${ }^{40-42}$ and $S_{8(\text { solid })}$ volume fraction are increased. ${ }^{52}$ With the qualitatively validated results, our model is used to perform a prospective study of the roles of various microstructural design parameters, such as the inter-particular poros-

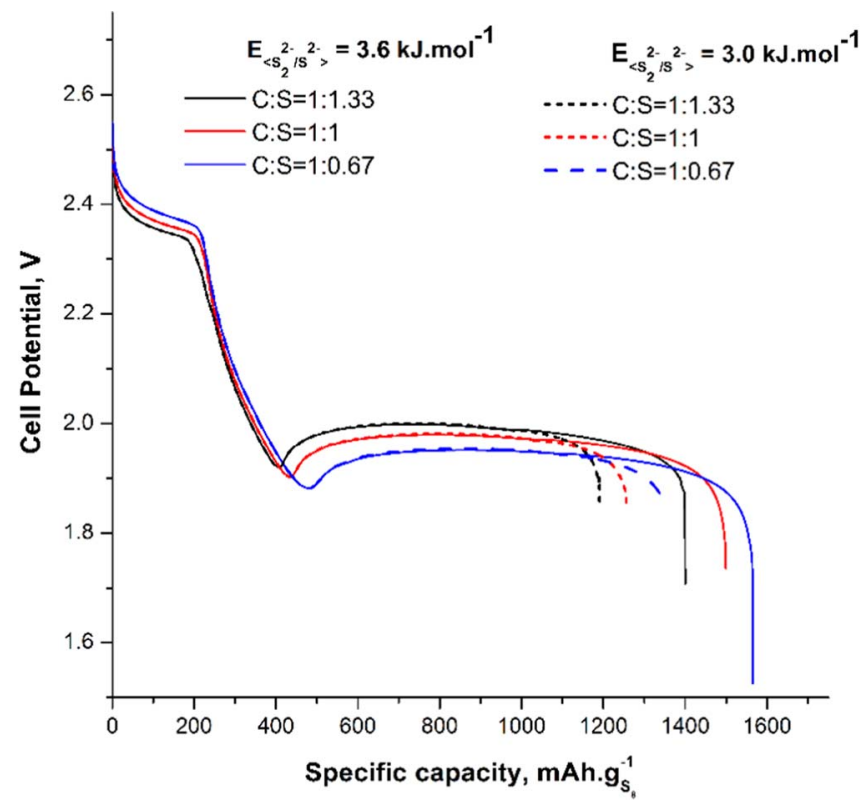

Figure 14. Simulated discharge profiles for cathodes with different $\mathrm{C} / \mathrm{S}$ volume ratio discharged at $1.0 \mathrm{~mA} . \mathrm{cm}^{-2}$ with $E_{\left\langle S_{2}^{2-} / S^{2-}\right\rangle}=3.6 \mathrm{~kJ}^{2} \mathrm{~mol}^{-1}$ (solid

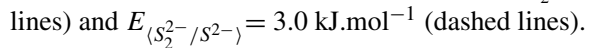

ity, the mesoporosity, the particle and pore sizes, etc. on the final cell performance. Substantial experimental efforts are currently in progress in our laboratory to ultimately validate these results. A sensitivity analysis of the activation energy of the $S_{2(\text { soln })}^{2-} / S_{(\text {soln })}^{2-}$ reduction reaction shows that the discharge capacity decreases as the activation energy is decreased. However, the predicted discharge capacity trends and the capacity limiting mechanisms for different cathode designs remain the same. The discharge capacity of the cathode with the larger particles decreases substantially as the escape function is decreased, since its capacity is mainly limited by the choking of mesopores by the $\mathrm{Li}_{2} \mathrm{~S}_{(\text {solid })}$ film formed over the carbon particles. In all the other cathode designs, the discharge capacities are shown to be affected by clogging of inter-particular pores, caused by
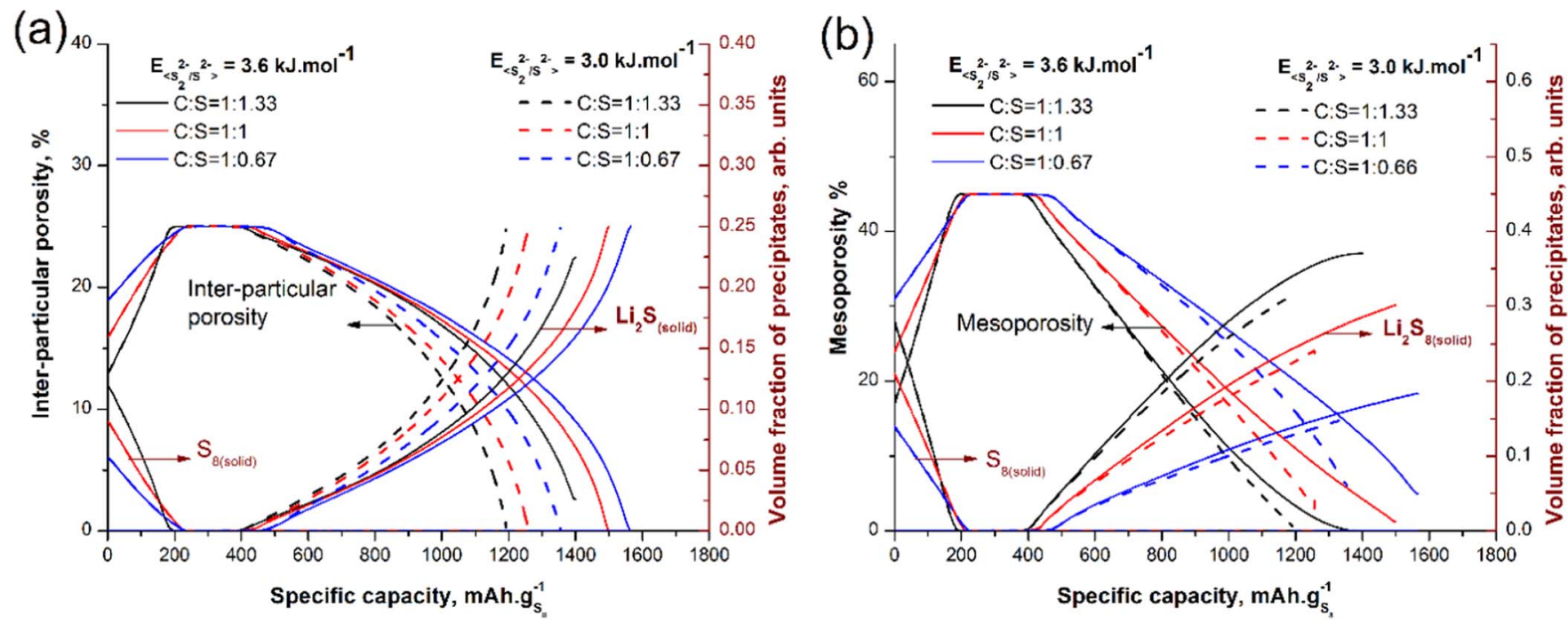

Figure 15. Calculated evolution of the porosities and the volume fractions of $S_{8(\text { solid })}$ and $L i_{2} S_{(\text {solid) }}$ in the (a) inter-particular pores, and (b) mesopores, both for the cathode bin closest to the separator. Solid lines correspond to $E_{\left\langle S_{2}^{2-} / S^{2-}\right\rangle}=3.6 \mathrm{~kJ}^{2} \mathrm{~mol}^{-1}$ and dashed lines correspond to $E_{\left\langle S_{2}^{2-} / S^{2-}\right\rangle}=3.0 \mathrm{~kJ}$.mol ${ }^{-1}$. 
transport limitations. The cathode with $35 \%$ maximum inter-particular porosity, $45 \%$ mesoporosity and $1: 1 \mathrm{C} / \mathrm{S}$ ratio provided the highest capacity, suggesting that increasing the inter-particular porosity, reducing the transport limitations, and/or increasing the mesoporous surface, reducing the accumulation of $L i_{2} S_{(\text {solid) }}$ in the inter-particular pores, should improve the performance. On the other hand, the cathode microstructure must be appropriately tailored to improve the discharge performance of the cathodes with larger $S_{8(\text { solid })}$ volume fraction.

In future, we are planning to refine the $\mathrm{Li}_{2} \mathrm{~S}$ growth model by using Kinetic Monte Carlo simulations ${ }^{50,53,54}$ and to upgrade the transport part of our model by using the highly concentrated solution theory.

\section{Acknowledgments}

The authors deeply acknowledge the European Union's FP7 and Horizon 2020 research and innovation programmes for the funding support through the EUROLIS project under grant agreement No.314515 and the HELIS project under grant agreement No. 666221. Dr. Charles Delacourt and Garima Shukla at LRCS are gratefully acknowledged for fruitful discussions.

\section{Appendix: Numerical Schemes}

The discretized form of the Eq. 13 is derived by applying a second order finite volume method as follows

$$
\left(I d-\frac{\Delta t}{2(\Delta x)^{2}} M^{n+1}\right)\left(c_{1} \varepsilon_{1}\right)^{n+1}=\left(I d+\frac{\Delta t}{2(\Delta x)^{2}} M^{n}\right) c_{1}{ }^{n}+\Delta t\left(g_{1}{ }^{n}-G_{1}{ }^{n}+f^{n}\right)
$$

where

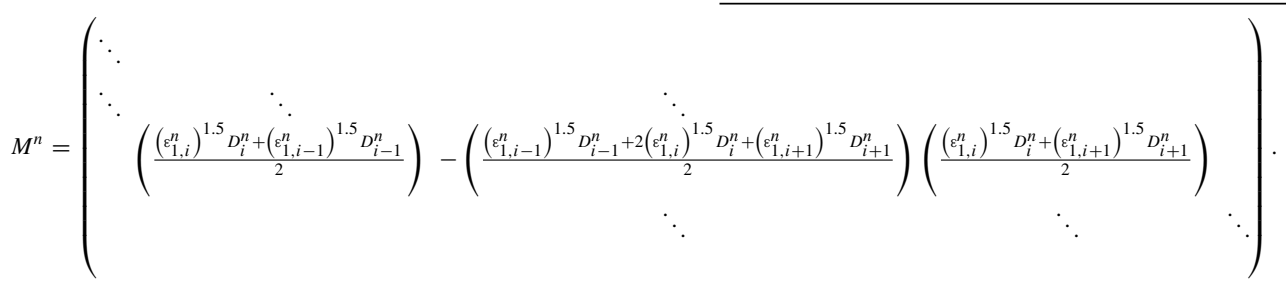

Here Id denotes the identity matrix, $\mathrm{i}$ and $\mathrm{n}$ respectively are the spatial and temporal indexes, $\Delta t$ is the time step and $\Delta x$ is the length of the control volume element.

At the anode/separator interface (at $x=0$ in Figure 1) the fluxes of all the dissolved species is zero, except for $\mathrm{Li}_{(\text {soln })}^{+}$which is given by

$$
N_{(i)}^{n}=\frac{i_{\langle 1\rangle}^{n}}{F} \text { at } x=0
$$

where $i_{\langle 1\rangle}^{j}$ is the faradaic current density of the lithium oxidation reaction at the anode (Table I).

The fluxes for all the dissolved species are continuous at the separator/cathode (at $x=L_{\text {sep }}$ ) interface is continuous, therefore fluxes of the species entering the cathode are equal to the those leaving the separator, which is given as

$$
N_{(i), \text { sep }}^{n}=N_{(i), \text { cat }}^{n}=\left(\varepsilon_{P+\frac{1}{2}}^{n}\right)^{1.5} D_{P+\frac{1}{2}}^{n}\left(\frac{\partial c}{\partial x}\right)_{P+\frac{1}{2}}^{n} \text { at } x=L_{\text {sep }}
$$

where $P+1$ is the cathode bin closest to the separator (Figure 1).

Finally, at the cathode/current collector interface $\left(x=L_{\text {sep }}+L_{\text {cat }}\right)$ the fluxes of all

\begin{tabular}{|c|c|c|}
\hline Symbol & Parameter name & Unit \\
\hline$E_{\mathrm{F}}$ & Activation energy for forward reaction & $\mathrm{J} \cdot \mathrm{mol}^{-1}$ \\
\hline$e_{f}$ & $\begin{array}{l}\text { Volume fraction of solid species forming } \\
\text { thin film }\end{array}$ & - \\
\hline$e_{\mathrm{k}}$ & Volume fraction of solid species & - \\
\hline$F$ & Faraday constant & $\mathrm{C} \cdot \mathrm{mol}^{-1}$ \\
\hline$f$ & Intra-flux & $\mathrm{mol} \cdot \mathrm{m}^{-3} \cdot \mathrm{s}^{-1}$ \\
\hline$G$ & Dissolution/precipitation reaction rate & $\mathrm{mol} \cdot \mathrm{m}^{-3} \cdot \mathrm{s}^{-1}$ \\
\hline$g$ & Electrochemical generation rate & $\mathrm{mol} \cdot \mathrm{m}^{-3} \cdot \mathrm{s}^{-1}$ \\
\hline$h$ & Planck constant & $\mathrm{J} \cdot \mathrm{s}$ \\
\hline$I_{\mathrm{G}}$ & Galvanostatic current density & $\mathrm{A} \cdot \mathrm{m}^{-2}$ \\
\hline$K^{\mathrm{a}}$ & Anodic pre-factor in rate equation & $s^{-1}$ \\
\hline$K^{\mathrm{c}}$ & Cathodic pre-factor in rate equation & $s^{-1}$ \\
\hline$k$ & Boltzmann constant & $\mathrm{J} \cdot \mathrm{K}^{-1}$ \\
\hline$L_{\text {cat }}$ & Cathode thickness & M \\
\hline$L_{\text {sep }}$ & Separator thickness & $\mathrm{m}$ \\
\hline$M$ & Molar mass & $\mathrm{kg} \cdot \mathrm{mol}^{-1}$ \\
\hline$N_{\mathrm{p}}$ & Number of micropores in a carbon particle & - \\
\hline$n$ & Amount of substance & mol \\
\hline$P$ & Number of bins in the separator & - \\
\hline$p$ & Anodic coefficient matrix & - \\
\hline$Q$ & Number of bins in the cathode & - \\
\hline$q$ & Cathodic coefficient matrix & - \\
\hline$R$ & Universal gas constant & $\mathrm{J} \cdot \mathrm{mol}^{-1} \cdot \mathrm{K}^{-1}$ \\
\hline$R_{\mathrm{p}}$ & Carbon particle radius & $\mathrm{m}$ \\
\hline$r_{\mathrm{p}}$ & Radius of micropore & $\mathrm{m}$ \\
\hline$s$ & $\begin{array}{l}\text { Coefficient matrix for electrochemical } \\
\text { reactions }\end{array}$ & - \\
\hline$T$ & Temperature & $\mathrm{K}$ \\
\hline$t$ & Time & $\mathrm{s}$ \\
\hline$U_{\text {cell }}$ & Cell voltage & $\mathrm{V}$ \\
\hline
\end{tabular}
the dissolved species is equal to zero.

\section{List of Symbols}

\begin{tabular}{lll} 
Symbol & \multicolumn{1}{c}{ Parameter name } & \multicolumn{1}{c}{ Unit } \\
\hline$A$ & Area factor in transition state theory & $\mathrm{m}^{-2}$ \\
$a$ & Specific surface area & $\mathrm{m}^{-1}$ \\
$c$ & Concentration & $\mathrm{mol} \cdot \mathrm{m}^{-3}$ \\
$c_{\text {ref }}$ & Reference concentration & $\mathrm{mol} \cdot \mathrm{m}^{-3}$ \\
$D$ & Diffusion coefficient & $\mathrm{m} \cdot \mathrm{s}^{-1}$ \\
$E_{\mathrm{B}}$ & Activation energy for backward reaction & $\mathrm{J} \cdot \mathrm{mol}^{-1}$
\end{tabular}


5. X. Ji and L. F. Nazar, J. Mater Chem, 20, 9821 (2010).

6. S. S. Zhang, J. Power Sources, 231, 153 (2013).

7. Y. X. Yin, S. Xin, Y. G. Guo, and L. J. Wan, Angew. Chem. - Int. Ed., 52, 13186 (2013).

8. S. S. Jeong et al., J. Power Sources, 174, 745 (2007)

9. P. G. Bruce, S. a. Freunberger, L. J. Hardwick, and J.-M. Tarascon, Nat. Mater, 11 $172(2011)$

10. E. Peled, Y. Sternberg, A. Gorenshtein, and Y. Lavi, J. Electrochem. Soc., 136, 1621 (1989).

11. C. Liang, N. J. Dudney, and J. Y. Howe, Chem. Mater, 21, 4724 (2009).

12. B. Zhang, X. Qin, G. R. Li, and X. P. Gao, Energy Environ. Sci., 3, 1531 (2010).

13. J. Guo, Y. Xu, and C. Wang, Nano Lett., 11, 4288 (2011).

14. L. Ji et al., J. Am. Chem. Soc., 133, 18522 (2011).

15. S. Xin et al., J. Am. Chem. Soc., 134, 18510 (2012).

16. Y. Yang, G. Zheng, and Y. Cui, Chem. Soc. Rev., 42, 3018 (2013).

17. Z. Wei Seh et al., Nat. Commun., 4, 1331 (2013).

18. G. Zhou et al., Adv. Mater, 26, 625 (2014).

19. S.-K. Jeong et al., Electrochem. Commun., 31, 24 (2013).

20. S.-K. Lee et al., Nano Lett., 15, 2863 (2015).

21. X. Liang et al., Nat. Commun., 6, 1 (2015).

22. X. Liang, A. Garsuch, and L. F. Nazar, Angew. Chem. Int. Ed., 54, 3907 (2015).

23. C. Wang et al., Nano Lett., 15, 1796 (2015).

24. J. Gao, M. A. Lowe, Y. Kiya, and D. Abru, J. Phys. Chem. C., 115, 25132 (2011)

25. Y. V Mikhaylik and J. R. Akridge, J. Electrochem. Soc., 151, A1969 (2004).

26. D. Moy, A. Manivannan, and S. R. Narayanan, J. Electrochem. Soc., 162, A1 (2015).

27. X. Ji, K. T. Lee, and L. F. Nazar, Nat. Mater, 8, 500 (2009).

28. T. F. Fuller, M. Doyle, and J. Newman, J. Electrochem. Soc., 141, 1 (1994).

29. A. A. Franco, RSC Adv., 3, 13027 (2013).

30. A. A. Franco, M. L. Doublet, and W. G. Bessler, Eds., Physical Multiscale Modeling and Numerical Simulation of Electrochemical Devices for Energy Conversion and Storage: From Theory to practice, p. 249, Springer, London, (2015).

31. K. Kumaresan, Y. Mikhaylik, and R. E. White, J. Electrochem. Soc., 155, A576 (2008)
32. J. P. Neidhardt et al., J. electrochem. Soc., 159, 1528 (2012).

33. D. N. Fronczek and W. G. Bessler, J. Power Sources, 244, 183 (2013).

34. A. F. Hofmann, D. N. Fronczek, and W. G. Bessler, J. Power Sources, 259, 300 (2014).

35. M. Ghaznavi and P. Chen, J. Power Sources, 257, 402 (2014).

36. M. Ghaznavi and P. Chen, J. Power Sources, 257, 394 (2014).

37. M. Ghaznavi and P. Chen, Electrochimica Acta, 137, 575 (2014).

38. T. Danner, G. Zhu, A. F. Hofmann, and A. Latz, Electrochimica Acta, 184, 124 (2015).

39. A. D. Dysart et al., J. Electrochem. Soc., 163, 730 (2016).

40. N. Jayaprakash, J. Shen, S. S. Moganty, A. Corona, and L. A. Archer, Angew. Chem.Int. Ed., 50, 5904 (2011).

41. J. Shim, K. A. Striebel, and E. J. Cairns, J. Electrochem. Soc., 149, 1321 (2002)

42. S.-E. Cheon et al., J. Electrochem. Soc., 150, A800 (2003).

43. D. A. G. Bruggeman, Ann. Phys., 24, 636 (1935).

44. B. Y. M. Kunitz, J. Gen. Physiol., 9, 715 (1926).

45. K. Xue, T. Nguyen, and A. A. Franco, J. Electrochem. Soc., 161, 3028 (2014).

46. K. Xue, E. Mcturk, L. Johnson, P. G. Bruce, and A. A Franco, J. Electrochem. Soc., 162, 614 (2015)

47. M. A. Quiroga, K.-H. Xue, T.-K. Nguyen, M. Tułodziecki, H. Huang, and A. A. Franco, Electrochem. Soc., 161, E3302 (2014).

48. T. Zhang, M. Marinescu, L. O'Neill, M. Wild, and G. Offer, Phys. Chem. Chem. Phys., 17, 22581 (2015).

49. Z. Deng et al., J. Electrochem. Soc., 160, A553 (2013).

50. M. A. Quiroga and A. A. Franco, J. Electrochem. Soc., 162, E73 (2015).

51. N. A. Cañas, S. Wolf, N. Wagner, and K. A. Friedrich, J. Power Sources, 226, 313 (2013)

52. N. Ding, S. Wei, T. S. A. Hor, Z. Liu, and Y. Zong, J. Power Sources, 269, 111 (2014).

53. G. Blanquer, Y. Yin, M. A. Quiroga, and A. A. Franco, J. Electrochem. Soc., 163, A329 (2016).

54. M. A. Quiroga, K. Malek, and A. A. Franco, J. Electrochem. Soc., 163, F59 (2016) 